Research Article

\title{
Seepage Evolution Model of the Fractured Rock Mass under High Seepage Pressure in Dam Foundation
}

\author{
Erfeng Zhao $\mathbb{D}^{1,2}$ and Yufeng Jiang $\mathbb{D}^{2}$ \\ ${ }^{1}$ State Key Laboratory of Hydrology Water Resources and Hydraulic Engineering, Hohai University, Nanjing 210098, China \\ ${ }^{2}$ National Engineering Research Center of Water Resources Efficient Utilization and Engineering Safety, Hohai University, \\ Nanjing 210098, China \\ Correspondence should be addressed to Erfeng Zhao; zhaoerfeng@hhu.edu.cn
}

Received 6 August 2020; Revised 6 December 2020; Accepted 3 February 2021; Published 13 February 2021

Academic Editor: Loke Foong

Copyright (c) 2021 Erfeng Zhao and Yufeng Jiang. This is an open access article distributed under the Creative Commons Attribution License, which permits unrestricted use, distribution, and reproduction in any medium, provided the original work is properly cited.

\begin{abstract}
The seepage of the fractured rock mass in dam foundations involves complex fluid-structure coupling behavior, due to practical hydrogeological conditions. In this work, the seepage characteristics of the fractured rock mass and their correlations with the structural permeable mediums are experimentally explored to reveal the cracking effect on the hydromechanical properties firstly. Subsequently, the tangential and the compression creep damage constitutive models are, respectively, established by introducing a nonlinear viscoplastic body to improve the Nishihara model. Afterwards, an innovative evolution equation of the permeability coefficient considering the creep damage is proposed. It can indicate the time effect of the porosity, the permeability, and damage variables of the fractured rock mass under the long-term infiltration action of the hydraulic pressures. Ultimately, the proposed methods are applied to the seepage simulation on the dam foundation of the Longyangxia hydropower station and the significantly increased leakage is in good agreement with the measured values during the storage period. It was further confirmed that the crack expansion and penetration in the rock masses can be constantly intensified by the seepage pressures. The research results can provide a reference for engineering repair and supervision through controlling the permeability performance for longterm operations.
\end{abstract}

\section{Introduction}

Dam foundations are often located in high geostress and high hydraulic pressure environment with extremely complex hydrogeological conditions [1-3]. A large part of the deformation of the rock mass is primarily caused by various weak intercalations and geological faults. The mechanical evolution of the faults can obviously affect the leakage quantity, and the variation of the seepage field will change the internal fluid pressures [4-6]. Under the long-term seepage actions, the cracks in the fractured rock mass expand continuously and the seepage resistance decreases correspondingly to formulate low-resistance seepage channels. They can cause the stress redistribution, weaken the mechanical strength, and damage the stability. For example, the primary cause of the Malpasset dam failure was the stress concentration in local zones in the foundation during water storage [7]. Moreover, in the Meishan reservoir, the lateral seepage pressure on the weak intercalations increased gradually during high-water level operation and caused the arch stacks to move sideways abnormally in 1962 [8].

In practical engineering projects, the seepage in the fractured rock mass involves complex fluid-structure coupling behavior $[9,10]$ and can usually be generalized to the seepage in fractured networks [11-13]. The coupling behavior between the seepage field and the stress field was simulated by Zhang et al. [14] using extended finite element method. Shi and Yang [15] established a coupled flow model to simulate the seepage property and the structural evolution of the fractured rock mass. The hydromechanical effect was studied by Figueiredo et al. [16] to characterize the permeability change at $1000 \mathrm{~m}$ deep rock mass. Gan and 
Elsworth [17] presented a continuum coupled model on the stress and the fluid flow in the fractured rock mass. Liu et al. [18] developed a numerical approach to estimate the shear effects on the fluid flow in the fractured networks. Pappalardo [19] acknowledged that the cooling behavior could affect the hydraulic conductivity by the infrared thermography. Furthermore, various numerical modelling methods of the seepage flow have been proposed and implemented to reveal the complex mechanism. Ren et al. [20] proposed an equivalent permeability method for modelling the fluid flow numerically. Sundararajan and Sankaran [21] developed a groundwater flow and transport model to estimate the seepage loss of Musi basin through simulation. Zhang et al. [22] produced physical models to simulate the seepage flow behavior in rough fractures with different fractal dimensions. The aforementioned studies have promoted further development of the seepage models on the fractured rock mass.

Owing to various disturbances in dam foundations, the propagation of microcracks and joint fissures in the fractured rock mass produce strong heterogeneity and nonlinearity of flow characteristics [23-26]. Relevant experimental studies are generally subject to technical means of obtaining effective and implicit test information [27, 28], including structural properties, seepage deformations, and seepage patterns. Considering the correlation verification of multidimension test methods, it is urgent to study the seepage evolution characteristics of the fractured water and the structural control effect. In addition, the seepage of the fractured rock mass owns obvious characteristics of dynamic evolution due to the transformation of the seepage pressures $[29,30]$. Few achievements have been made on the seepage damage effect of the foundation rock mass in controlling its permeability performance.

In this study, the seepage characteristics of the fractured rock mass and their correlations with the structural permeable mediums are firstly extracted by combining with seepage tests in Section 2. Secondly, a nonlinear viscoplastic body is newly introduced to improve the Nishihara model to establish novel creep damage constitutive models in Section 3. Thirdly, an innovative seepage evolution model considering the creep damage is proposed in Section 4. The proposed methods are finally validated and applied to simulate the seepage evolution of the practical dam foundation in Section 5 .

\section{Seepage Characteristics of the Fractured Rock Mass}

According to triaxial compression tests of the fractured rock, the progressive failure is often accompanied by the compression, crack, expansion, and mutual intersection of internal fractures $[31,32]$. The permeability changes obviously with the formation of the fractured networks, owing to the expansion and the penetration of primary cracks. They can formulate seepage channels in the conglomerate and decrease the seepage resistance, resulting in the enhancement of the permeability.
2.1. Permeability of the Soft and Hard Rocks. Under certain constraint pressures and pore pressures, the permeability change can be obtained by rock electrohydraulic servocontrolled permeability tests (Figure 1(a)) through applying axial pressures gradually [33]. The permeability evolutions of the hard and soft rocks in the whole stress-strain process are shown in Figure $1[34,35]$. Figure 1 reflects the close relationship between the permeability and the displacement, indicating the permeability change in different stages. In the elastic stage (primary microcrack closure stage), the permeability coefficient decreases slightly with the increase of the axial stress. After entering the nonlinear strain hardening stage, the permeability coefficient gradually increases and its maximum lags behind the peak strength, due to the propagation of microcracks and the new formation of macrocracks. Subsequently, with the increase of the axial strain, the permeability coefficient may continue to increase and decrease gradually or sharply, depending on rock types, fabric, and void development. The soft rock shows strong plastic rheology after failure and the permeability attenuation range is generally large, while the permeability of the hard rock is relatively stable after failure, with a small change range. They are both caused by the internal correlations between the rock permeability and the crack propagation.

2.2. Permeability of the Fractured Rock Mass. The permeability measurement of the fractured rock mass can be obtained by laboratory permeability tests or in situ water pumping tests. The seepage pressure and the fractured permeability channel shape are two critical factors affecting the seepage evolution of the fractured rock mass.

(1) According to the laboratory test results (Figure 2) [34], the seepage-guiding state of the penetrated fracture channel is generally characterized by the high seepage resistance, and the seepage of the fractured network is turbulent. Under certain seepage pressures, the seepage velocity decreases with the increase of the seepage channel width, while the seepage pressure along the fractured network gradually decreases with the increase of the seepage distance. They indicate that the decrease of the seepage pressure and the increase of the seepage resistance are correlated and can be transformed.

(2) In in situ water pumping tests $[34,35]$, the selected sections include the normal fault zone, the reverse fault zone, and the unloading disturbance zone. The dual-porosity seepage method is taken to test the correlations of the exerted water pressures and the flow duration change under high seepage pressures. The whole process of the rock mass reaching the conduction seepage state is shown in Figure 3. The permeability primarily depends on structural planes, that is, the permeability and mechanical characteristics of the fractures change synchronously. Meanwhile, the mechanical, physical, and chemical effects of the internal water in the fractures, microcracks, and rock pores can decrease the 

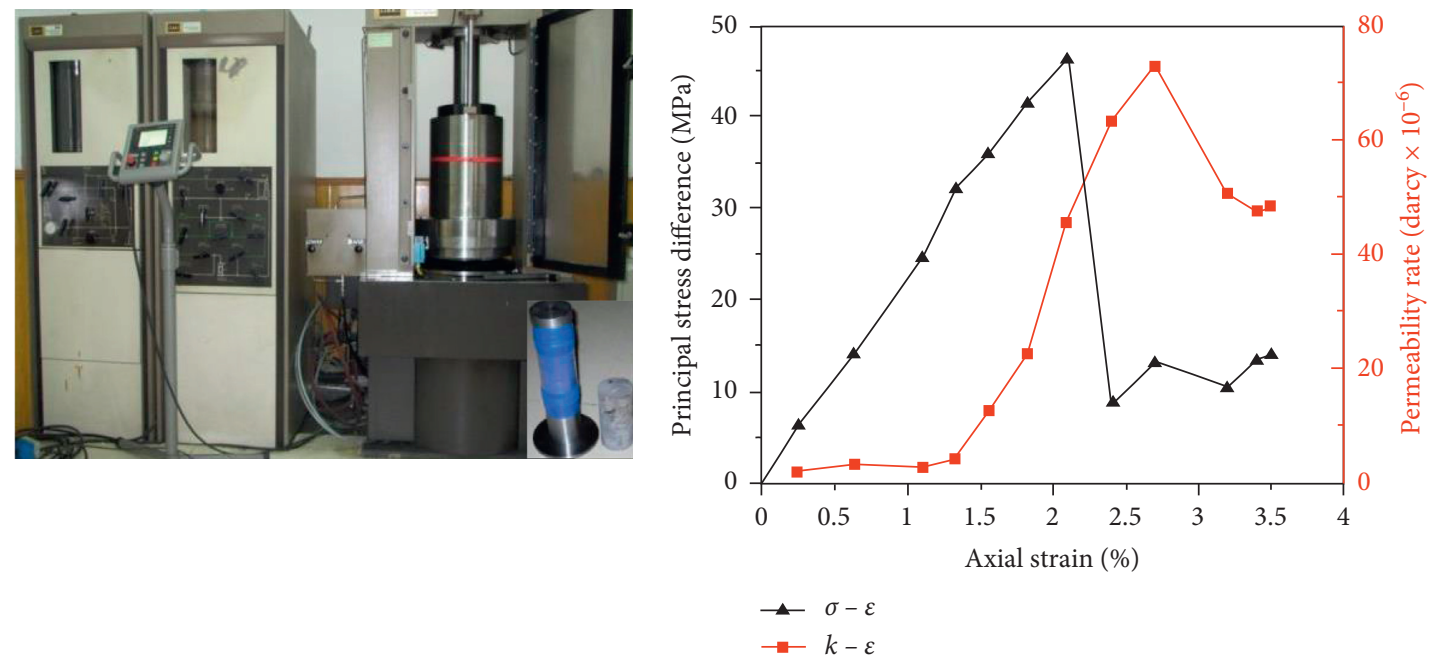

(a)

(b)

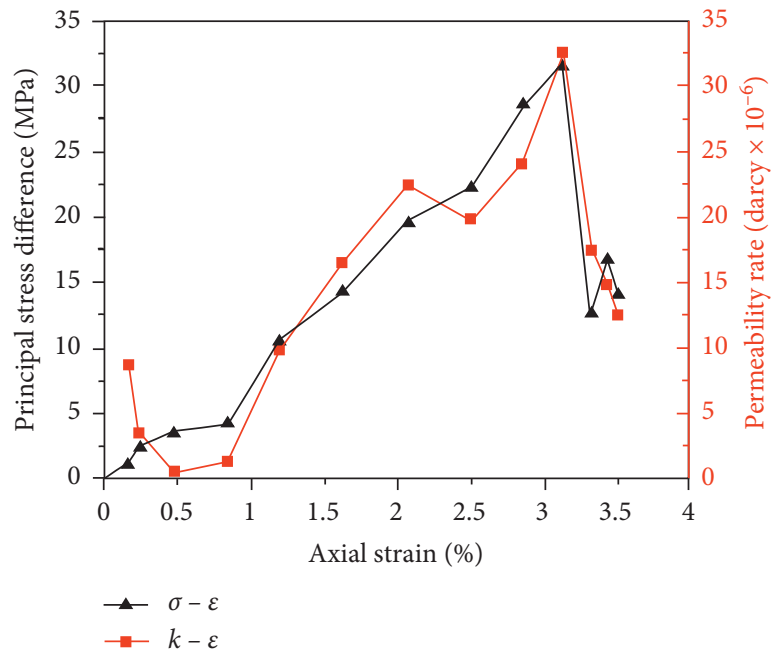

(c)

Figure 1: Permeability variations of the hard and soft rocks. (a) Electrohydraulic servocontrolled testing system; (b) hard rock: fine sandstone; (c) soft rock: bauxite.

structural strength. Moreover, the additional seepage volume force will also change the rock mass displacement and adjust the internal stress states.

The in situ test results can indicate the permeability of the rock masses in practical geological conditions. As shown in Figure 3, the seepage evolution and the structural control effect can be regarded as the essential basis for evaluating the permeability and antiseepage failure strength of the fractured rock masses.

\section{Creep Damage Model of the Fractured Rock Mass}

In the dam foundations, the joints, fissures, and gaps are not only the migration channels of the groundwater but also the primary mediums of the foundation deformation. The displacement increases with time under continuous loads [36]. Hence, the interior fluid flow is mainly controlled by the structural properties and the connectivity of the fractured networks. The test results of the granite foundation of the Huangdeng Dam are shown in Figure 4 [37], including the initial strain, as well as the steady and accelerated creep strain under different confining pressures. In Figure 4(a), the irreversible plastic deformation became clearer with the increase of the stress levels and the accumulation creep effect, indicating that the internal structure adjustment is more severe under the high axial stress levels. When the stress levels reached $100 \mathrm{MPa}$ and $120 \mathrm{MPa}$, respectively, the creep failure occurred due to the damage accumulation. In Figure 4(b), under the confining stresses of $2 \mathrm{MPa}$ and $6 \mathrm{MPa}$, the seepage flow rates decreased remarkably, due to the variations of the fractures and pores under the initial loading, and they became stable gradually after $0.21 \mathrm{~h}$ and $0.44 \mathrm{~h}$, respectively.

Under the long-term infiltration action of high hydraulic pressures, the foundation creep leads to certain changes in microcracks of the rock mass and geometric shapes of the 


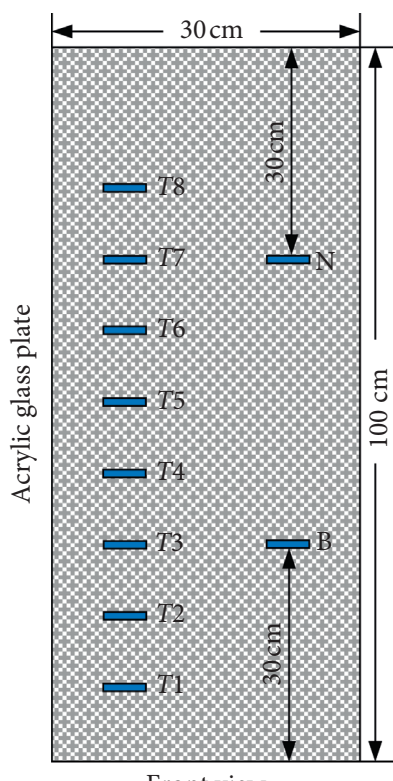

Front view

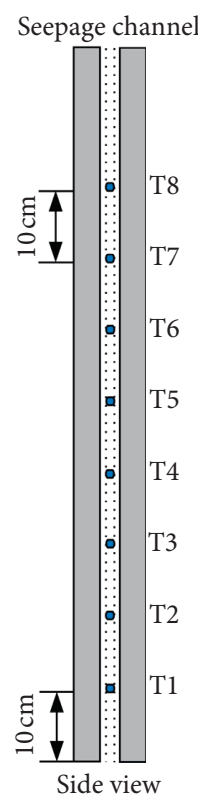

(a)

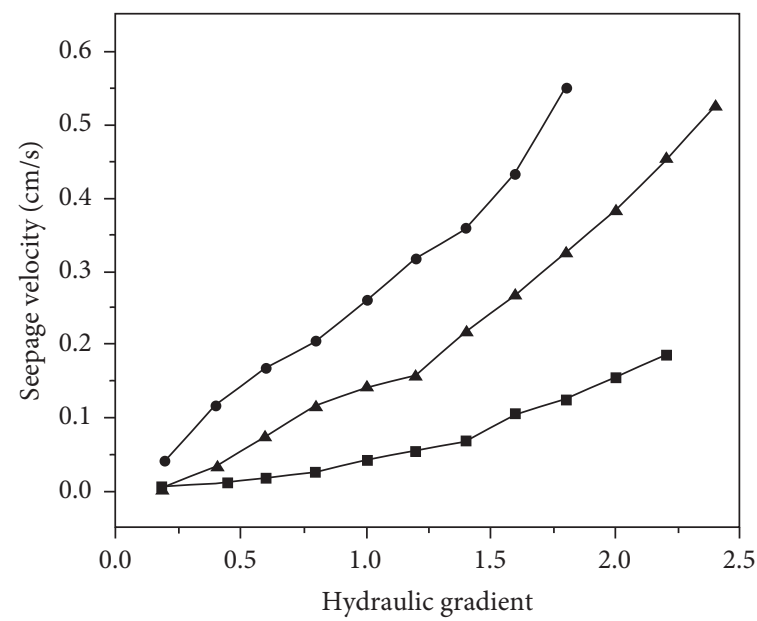

Diameter $(\mathrm{mm})$

$\rightarrow 0.5-0.7$

$\simeq 0.25-0.35$

$\rightarrow 0.12-0.25$

(b)

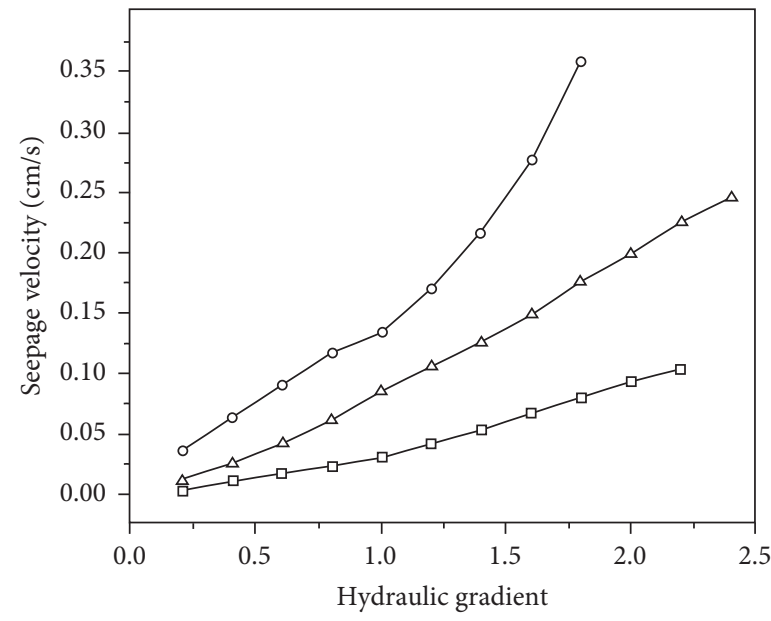

Diameter $(\mathrm{mm})$

$\rightarrow 0.5-0.7$

$\rightarrow 0.25-0.35$

$\rightarrow 0.12-0.25$

(c)

FIGURE 2: Influence of the seepage channel width and the particle size on the seepage velocity. (a) The seepage testing model using the acrylic glass and the battery carbon rods; (b) crack width: $2 \mathrm{~mm}$; (c) crack width: $5 \mathrm{~mm}$.

structural planes in the faults. They can affect the hydraulic conductivity and change the seepage laws. The creep effect can be simulated numerically combining with the bionic algorithms [38]. On the contrary, the change of the seepage field can cause the variation of the stress field and the creep of the dam foundation accordingly. As shown in Figure 4, the creep displacement finally tends to be stable when the shear load is small. It can be assumed that the fractured rock mass will not be damaged in the elastic stage and the damage only occurs after entering the viscoplastic stage. Karalar and Çavuşli $[39,40]$ simulated the creep settlements of the Ilisu concrete faced rockfill dam and the nonlinear seismic behaviors of the Boyabat concrete gravity dam with special viscoplastic models using the $\mathrm{FLAC}^{3 \mathrm{D}}$ software based on the finite difference method. Therefore, the creep damage model should contain the stress-strain constitutive equation and the damage evolution equation [41, 42]. Because the creep damage of the fractured rock mass can lead to stiffness deteriorating and strength weakening, the establishment of the damage function and the yield function should consider the damage evolution.

3.1. Creep Damage Function. The increase of the viscoplastic creep displacement is accompanied by the damage accumulation in Figure 4(a). The evolution equation of damage 


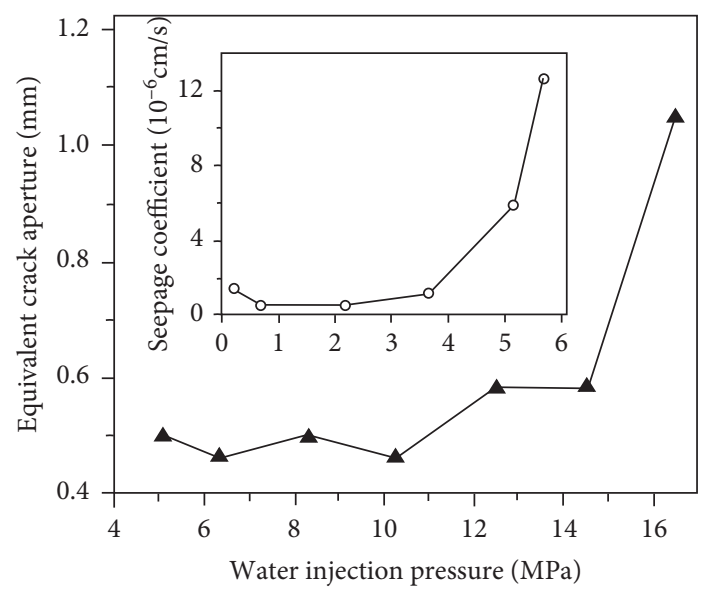

(a)

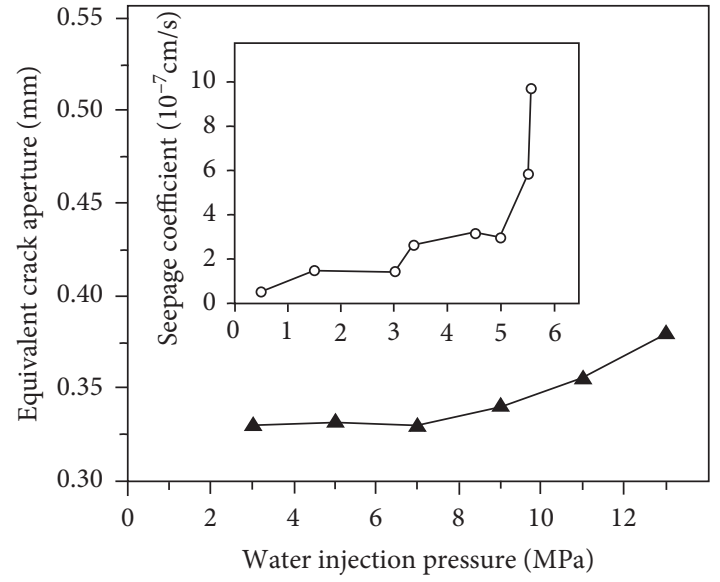

(b)

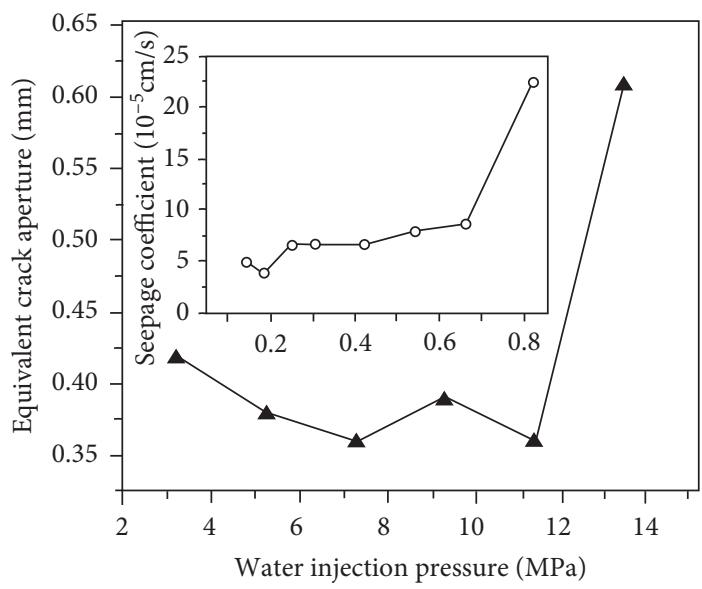

(c)

FIGURE 3: In situ water pumping tests on the fractured rock mass. (a) Normal fault; (b) reverse fault; (c) unloading disturbance zone.

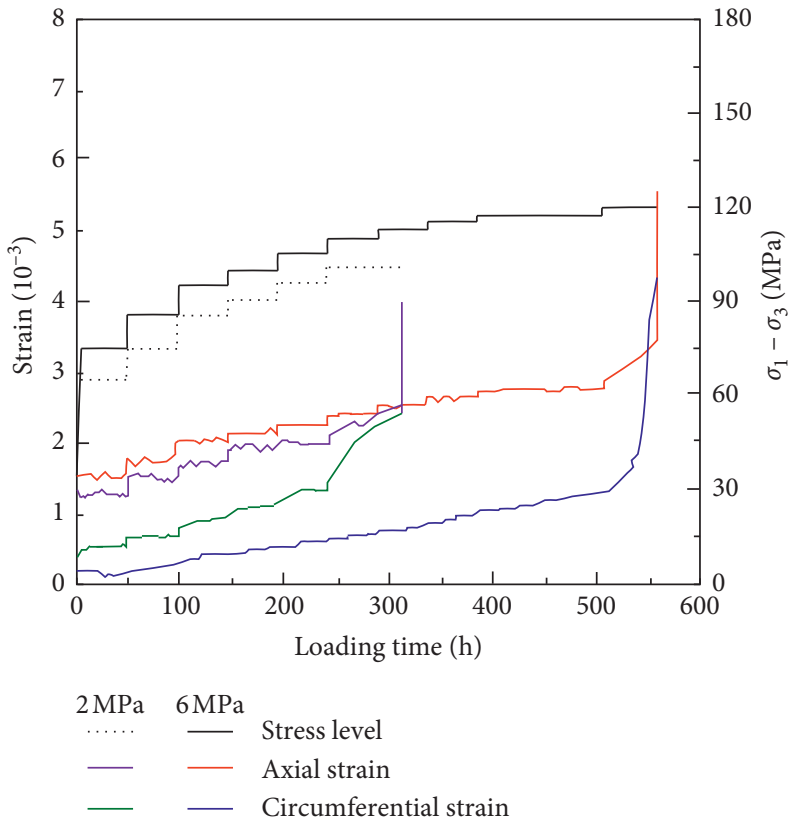

(a)

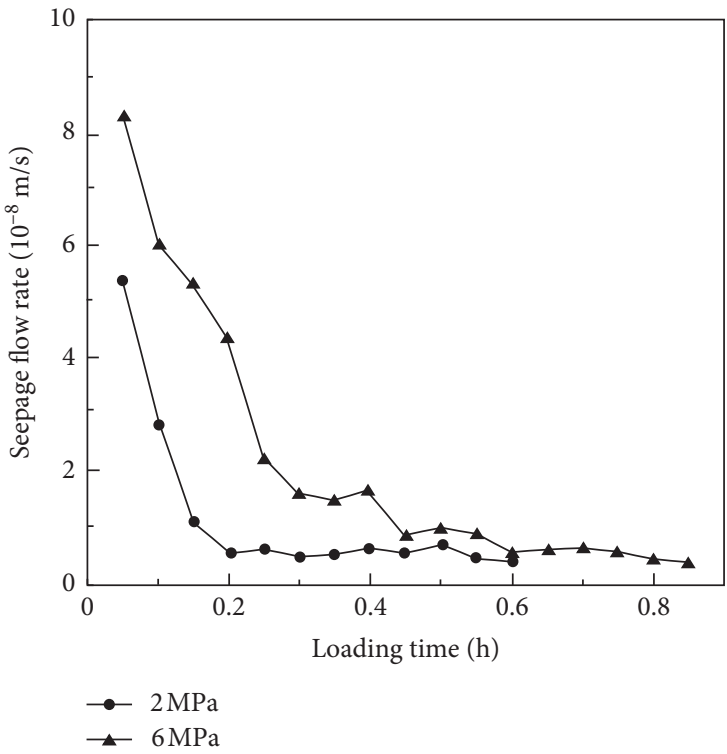

(b)

Figure 4: Test results of the granite foundation under different confining pressures. (a) Creep properties for volcanic breccia; (b) seepage flow rate at the instantaneous strain stage. 
variables should be firstly established to indicate the creep damage. According to the second law of thermodynamics, it is a function of the damage dissipation potential, defined as follows:

$$
\mathbf{D}=\mathbf{I}-\exp \left[-\mathbf{B}\left|Y-Y_{0}\right|^{1 / n}\right]
$$

where $\mathbf{I}$ is the unit matrix, $B$ and $n$ are material parameters, $\mathbf{Y}_{0}$ is the initial dissipated energy, and $\mathbf{Y}$ is the total dissipated energy after the creep damage.

Due to the functional relationship between the damage dissipation energy and the tangential plastic displacement, the elastic-plastic tangential damage $D_{\tau}$ and the normal damage $D_{v}$ are

$$
\left\{\begin{array}{l}
D_{\tau}=1-\exp \left(-\kappa \zeta_{D}^{R}\right) \\
D_{v}=1-\exp \left(-\kappa_{s} \zeta_{D}^{R_{s}}\right)
\end{array}\right.
$$

where $\kappa, R, \kappa_{s}$, and $R_{s}$ are material parameters and $\zeta_{D}$ is the plastic shear displacement.

Assuming that the shear stress in the complete damage is $\tau^{c}$ and the normal displacement is $v^{c}$, the following equation can be obtained:

$$
\left\{\begin{array}{l}
\tau^{a}=D_{\tau} \tau^{c}+\left(1-D_{\tau}\right) \tau^{i} \\
v^{a}=v^{e}+D_{v} v^{c}
\end{array}\right.
$$

where $\tau^{a}$ and $v^{a}$ are the actual shear stress and the normal displacement, respectively; $\tau^{i}$ is the shear stress without considering the damage.

Equation (3) is consistent with the elastic-plastic damage function. Because there is a functional relationship between the damage dissipation energy and its plastic work accumulation, the functional relationship between the creep damage dissipation energy and the viscoplastic displacement can be constructed, regardless of the normal displacement. Namely,

$$
\mathbf{Y}=a^{\prime}\left(\omega^{v p}\right)^{b^{\prime}}
$$

where $\omega^{v p}=\int\left(\mathrm{d} u^{\prime v p} \mathrm{~d} u^{\prime v p}+\mathrm{d} v^{v p} \mathrm{~d} v^{\prime v p}\right)^{1 / 2} ; \mathrm{d} u^{\prime v p}$ and $\mathrm{d} v^{\prime v p}$ are the viscoplastic displacement increments in the local axes of $x^{\prime}$ and $y^{\prime}$, respectively; $a^{\prime}$ and $b^{\prime}$ are the material parameters.

Assuming that the tangential damage is isotropic, without original damage, the evolution function of the tangential creep damage and the normal creep damage in the foundation faults can be defined as follows:

$$
\left\{\begin{array}{l}
D_{\tau}=1-\exp \left(-a\left|\omega^{v p}\right|^{b}\right), \\
D_{v}=1-\exp \left(-c\left|\omega^{v p}\right|^{d}\right),
\end{array}\right.
$$

where $a, b, c$, and $d$ are material parameters.

According to equation (5), the tangential and normal damage degrees are both equal to 0 when the viscoplastic displacement is 0 , while they are nearly 1.0 when the fractured rock mass is completely damaged. The friction coefficient of the fractured rock mass changes slightly after the shear damage and is $0.95-1$-fold of the original. When the cohesion almost disappears completely, only 0.1-0.2-fold of the original is preserved. The shear creep damage yield function is

$$
f=\tau+\mu \sigma_{n}-\alpha c
$$

where $\mu$ is the friction coefficient; $\sigma_{n}$ is the normal stress (the positive value represents the tensile stress and the compressive stress otherwise); $c$ is the cohesion; $\alpha$ is the damage function: $\alpha=1-D_{\tau}$. For the undamaged rock mass, $D_{\tau}=0$ and $\alpha=1$; consequently, $f=\tau+\mu \sigma_{n}-c$, the traditional Mohr-Coulomb yield criterion; with the increase of the creep displacement, $D_{\tau}$ increases, whereas $\alpha$ decreases until the rock mass is completely damaged; that is, $\alpha=0$ and $f=\tau+\mu \sigma_{n}$.

3.2. Creep Damage Constitutive Model. For the fractured rock mass under external loads, the tangential displacement is different from the normal one. The tangential model and the normal model of the creep damage should be established, respectively. The viscoelastic-plastic constitutive equation without considering the damage is

$$
\dot{\sigma}_{i j}=D_{i j k l}^{0}\left(\dot{\varepsilon}_{k l}-\dot{\varepsilon}_{k l}^{v p}\right) \text {, }
$$

where $D_{i j k l}^{0}$ is the stiffness tensor, $\dot{\sigma}_{i j}$ is the stress tensor rate, $\dot{\varepsilon}_{k l}$ is the total strain rate, and $\dot{\varepsilon}_{k l}^{v p}$ is the viscous strain rate.

According to the equivalent strain hypothesis, the viscoelastic-plastic damage constitutive equation can be deduced from equation (7), replacing the apparent stress by the effective stress.

$$
\dot{\sigma}_{i j}^{*}=D_{i j k l}^{0}\left(\dot{\varepsilon}_{k l}-\dot{\varepsilon}_{k l}^{v p}\right) .
$$

Assuming that the tangential elastic stiffness coefficient is $k_{x^{\prime}}^{i}=k_{y^{\prime}}^{i}=k_{s}^{i}$ under the positive stress $\sigma_{n}$ ( $x^{\prime}$ and $y^{\prime}$ are mutually perpendicular axes parallel to the structural planes) and that $k_{s}^{c}$ remains in the complete damage condition, the tangential elastic stiffness coefficient in the evolution is defined as follows:

$$
k_{s}=D_{\tau} k_{s}^{c}+\left(1-D_{\tau}\right) k_{s}^{i} .
$$

According to equation (8), the elastic strain rate can be deduced.

$$
\dot{\varepsilon}_{i j}^{e}=\dot{\varepsilon}_{i j}-\dot{\varepsilon}_{i j}^{v}=C_{i j k l}^{0} \dot{\sigma}_{k l}^{*},
$$

where $C_{i j k l}^{0}$ is the flexibility tensor.

When $C_{i j k l}^{0}$ is replaced by the flexibility tensor $C_{i j k l}^{0-d}$ of the damaged medium and the effective stress is replaced by the apparent stress $\sigma_{k l}$, the following equation can be obtained:

$$
\dot{\varepsilon}_{i j}^{e}=C_{i j k l}^{0-d} \dot{\sigma}_{k l}+\dot{C}_{i j k l}^{0-d} \sigma_{k l} \text {. }
$$

The elastic strain rate for the shear creep damage is

$$
\dot{\gamma}_{j}^{e}=\frac{1}{k_{s}} \dot{\tau}_{j}-\frac{1}{k_{s}^{2}} \dot{k}_{s} \tau_{j}=\frac{1}{k_{s}} \dot{\tau}_{j}+\frac{1}{k_{s}^{2}}\left(k_{s}^{i}-k_{s}^{c}\right) \dot{D}_{\tau} \tau_{j},
$$

where $j$ can be $x^{\prime}$ or $y^{\prime}$. 
When the shear stress is small in the fractured rock mass, the shear creep deformation tends to be stable, but the shear deformation after unloading is plastic and does not decrease with time, due to the relative slip and dislocation during the creep development. The tangential creep damage equation can be deduced by the model shown in Figure 5, through improving the Nishihara model with a nonlinear viscoplastic body. The elastic body simulates the instantaneous elastic deformation, the Kelvin body simulates the decaying creep deformation, the plastic body simulates the plastic yield, and the viscous body simulates the irreversible creep. The viscoelastic strain rate can be got according to the equivalent strain assumption.

$$
\dot{\gamma}_{j}^{v e}=\frac{\tilde{\tau}_{j}}{\eta_{k}} \exp \left(-\frac{k_{k}}{\eta_{k}} t\right),
$$

where $\tilde{\tau}_{j}$ is the effective shear stress: $\tilde{\tau}_{j}=\left(k_{s} / k_{s}^{i}\right) \tau_{j}=(1-$ $\left.D_{\tau}+\left(k_{s} / k_{s}^{i}\right) D_{\tau}\right) \tau_{j}$.

The viscoelastic strain can be got as follows:

$$
\gamma_{j, t+\Delta t}^{v e}=\gamma_{j, t}^{v e} \exp \left(-\frac{k_{k}}{\eta_{k}} \Delta t\right)+\frac{\tilde{\tau}_{j}}{k_{k}}\left[1-\exp \left(-\frac{k_{k}}{\eta_{k}} \Delta t\right)\right] \text {. }
$$

$$
Q=Q\left(\{\sigma\},\left\{\dot{\varepsilon}^{v p}\right\}\right)
$$

The viscoplastic flow rule is

$$
\dot{\gamma}_{j}^{v p}=\gamma<f>\frac{\partial Q}{\partial \tau_{j}},
$$

where $\gamma$ is the flow coefficient; $\left\langle f>= \begin{cases}f, & f>0, \\ 0, & f \leq 0 .\end{cases}\right.$

For the creep model shown in Figure $5, \gamma=1 / \eta_{s}$, where $\eta_{s}$ is the viscosity coefficient after the creep yield. The associated flow rule is adopted.

$$
\dot{\gamma}_{j}^{v p}=\gamma<f>\frac{\partial Q}{\partial \tau_{j}}=\frac{1}{\eta_{s}}<f>\frac{\partial Q}{\partial \tau_{j}}=\frac{1}{\eta_{s}}<f>\frac{\tau_{j}}{\sqrt{\tau_{x^{\prime}}^{2}+\tau_{y^{\prime}}^{2}}} .
$$

When $\tau_{x^{\prime}}$ and $\tau_{y^{\prime}}$ are constants and $f=\left(\tau_{x}^{2}+\tau_{y}^{2}\right)^{1 / 2}$ $+\mu \sigma_{z^{\prime}}-\left(1-D_{\tau}\right) c>0, \sigma_{z^{\prime}}$ is constant and $z^{\prime}$ is the axis perpendicular to the structural plane. With the accumulation of the creep damage, $f$ and $\dot{\gamma}^{v p}$ will increase, indicating the creep acceleration.

On this basis, the tangential creep damage constitutive equation can be deduced.

When the yielding phenomenon occurs, the plastic potential function $Q$ should be introduced:

$$
\begin{aligned}
& \dot{\gamma}_{j}=\dot{\gamma}_{j}^{e}+\dot{\gamma}_{j}^{v}+\dot{\gamma}_{j}^{v e}+\dot{\gamma}_{j}^{v p}=\frac{1}{k_{s}} \dot{\tau}_{j}+\frac{1}{k_{s}^{2}}\left(k_{s}^{i}-k_{s}^{c}\right) \dot{D}_{\tau} \tau_{j}+\frac{\left(1-D_{\tau}+\left(k_{s} / k_{s}^{i}\right) D_{\tau}\right)}{\eta_{M}} \tau_{j}+ \\
& {\left[\frac{\left(1-D_{\tau}+\left(k_{s} / k_{s}^{i}\right) D_{\tau}\right) \tau_{j}}{\eta_{k}}\right] \cdot \exp \left(-\frac{k_{k}}{\eta_{k}} t\right)+\frac{1}{\eta_{s}}<f>\frac{\tau_{j}}{\sqrt{\tau_{x^{\prime}}^{2}+\tau_{y^{\prime}}^{2}}} . }
\end{aligned}
$$

Influenced by the pores in the fractured rock mass, the significant compaction can be produced under the normal force, that is, the instantaneous elastic deformation occurs first, and then the creep rate decreases, and finally the creep deformation tends to be stable. Most of the normal compression deformation cannot be recovered after unloading. The attenuation creep characteristics along the normal direction can be simulated by the model shown in Figure 6 . The elastic body reflects the instantaneous deformation, the Kelvin body reflects the decay creep and the hysteresis recovery deformation after unloading, and the unrecoverable creep can be indicated by the viscous body. The normal displacement can be defined as

$$
\varepsilon_{z^{\prime}}=\varepsilon_{z}^{e}+\varepsilon_{z}^{v e}+D_{v} \varepsilon_{z}^{c},
$$

where the viscous displacement is

$$
\varepsilon_{z}^{v e}=\frac{\sigma_{z^{\prime}}}{k_{2, n}}\left(1-e^{-k_{2, n} / \eta_{n}}\right)+\int_{0}^{t} \frac{\sigma_{z^{\prime}}}{\eta_{M}(t)} \mathrm{d} t .
$$

In Figure 6, in addition to the instantaneous recovery during unloading, the hysteresis recovery time is actually determined by the two viscous bodies. The normal compression creep damage constitutive equation is

$$
\begin{aligned}
\varepsilon_{z^{\prime}}= & \frac{\sigma_{z^{\prime}}}{k_{n}}+\frac{\sigma_{z^{\prime}}}{k_{2, n}}\left(1-e^{-\left(k_{2, n} / \eta_{n}\right) t}\right) \\
& +\int_{t=0}^{t} \frac{\sigma_{z^{\prime}}}{\eta_{M}(t)} \mathrm{d} t+D_{v} \varepsilon_{z}^{0} \exp \left(-k \sigma_{z^{\prime}}\right) .
\end{aligned}
$$

\section{Seepage Evolution Model considering the Creep Damage}

Generally speaking, the seepage in the fractured rock mass conforms to Darcy's law, and the permeability coefficient is a critical index. The relationship between the porosity, the permeability, and damage variables is shown in Figure 7 [43], where $\beta$ is related to the moisture content and the temperature. The permeability gradually increases with the 


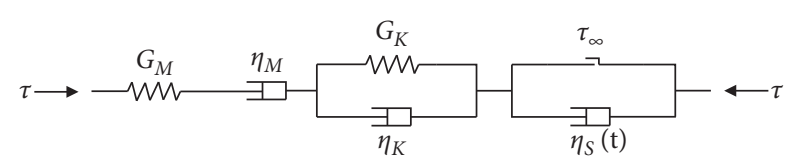

FIgURE 5: Shear creep model of the fractured rock mass.

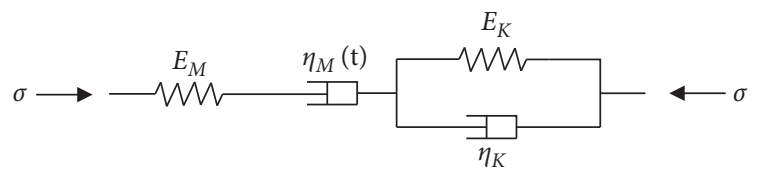

FIGURE 6: Normal compression creep model of the fractured rock mass.

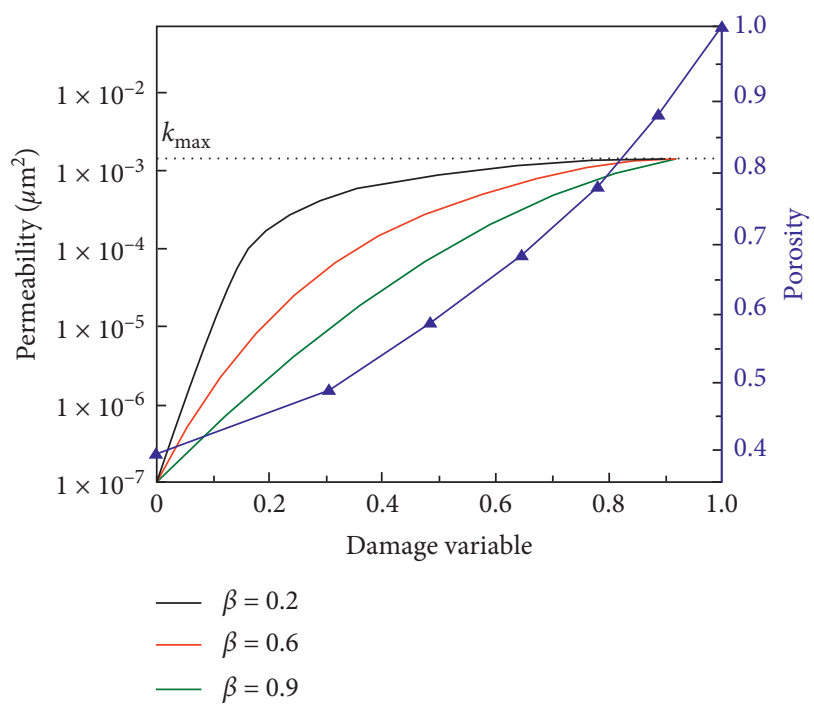

FIGURE 7: Relationship between porosity, permeability, and damage variables in the fractured rock mass.

damage accumulation and tends to be stable when the dominant penetrating pores are formed. Most previous porous media models assume that the porosity and the permeability coefficients are material constants independent of time. However, the gradual damage of the foundation rock mass (including the grouting curtain rock mass) will greatly affect the seepage evolution. Here, the influence of the creep damage on the permeability is used to characterize the increase of the hydraulic conductivity, which is primarily caused by the spatial change of the water flow inside the filling. The damage of the grouting curtain rock mass is used to characterize the degradation of its antiseepage function.

4.1. Evolution Equation of the Permeability Coefficient. As shown in Figure 8, the lengths of three sides of a damaged unit are $\mathrm{d} x_{1}, \mathrm{~d} x_{2}$, and $\mathrm{d} x_{3}$, and the anisotropic damage

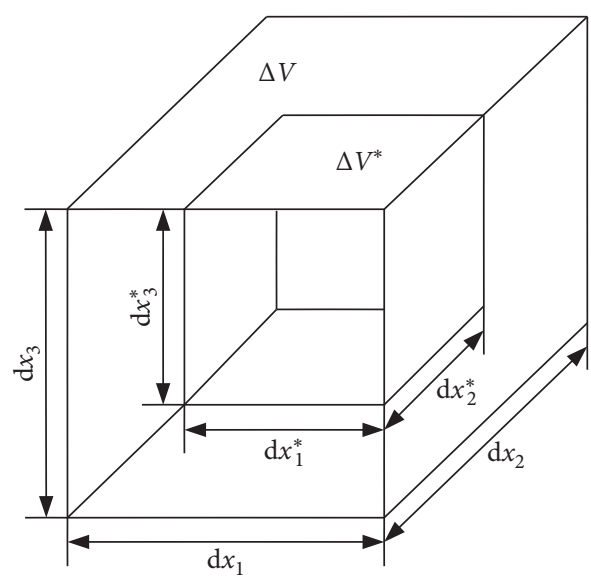

FIgURE 8: Diagram of a damaged unit.

characteristics can be indicated by the damage principal value. Damage variables are defined as

$$
D_{i}=\frac{A_{i}-A_{i}^{*}}{A_{i}}=\frac{\mathrm{d} s_{i}^{*}}{\mathrm{~d} x_{j} \mathrm{~d} x_{k}},
$$

where $D_{i}(i=1,2,3)$ is the primary damage variable; $\mathrm{d} s_{i}^{*}$ is the reduction area of the section surface $\mathrm{d} x_{i} \mathrm{~d} x_{k}$, caused by the porosity variation.

The relationship between the porosity $n$ and the damage variable $D$ is

$$
n=\left(D_{1} D_{2} D_{3}\right)^{1 / 2} \text {. }
$$

For isotropic materials, $D_{1}=D_{2}=D_{3}=D$ and $n=D^{3 / 2}$, the relationship between the change rate of the porosity and the damage developing rate is

$$
\dot{n}=\frac{3}{2} D^{1 / 2} \dot{D}
$$

According to equation (23), the porosity evolution can be described in view of the continuum damage mechanics due to the quantitative relationship between $n$ and $D$. Assuming that the permeability coefficient depends on the infilling properties, regarded as the porous rock, the isotropous permeability coefficient can be defined as

$$
k=\frac{g}{\mu} \frac{d^{2}}{180} \frac{n^{3}}{(1-n)^{2}},
$$

where $\mu$ is the viscosity coefficient, $d$ is the average size of solid particles, and $n$ is the porosity of the infillings.

Due to the variation of the porosity $n$ along the depth $z$, where $n=n(z)$, the permeability coefficient can be

$$
k(z)=\frac{g}{\mu} \frac{d^{2}}{180} \frac{[n(z)]^{3}}{[1-n(z)]^{2}} .
$$

Therefore, the relation equations of the permeability coefficient, the damage variable, and their change rates are 


$$
\begin{aligned}
k & =\frac{g}{\mu} \frac{d^{2}}{180} \frac{D^{9 / 2}}{\left(1-D^{3 / 2}\right)^{2}}=\frac{g}{\mu} \frac{d^{2}}{180} \frac{D^{9 / 2}}{1-2 D^{3 / 2}+D^{3}}, \\
\dot{k} & =\frac{g}{\mu} \frac{d^{2}}{180} \frac{3 n^{2}(1-n)^{2} \dot{n}+2 n^{3}(1-n) \dot{n}}{(1-n)^{4}} \\
& =\frac{g}{\mu} \frac{d^{2}}{180} \frac{9 D^{7 / 2}\left(1-2 D^{3 / 2}+D^{3}\right) \dot{D}+6 D^{5}\left(1-D^{3 / 2}\right) \dot{D}}{2\left(1-D^{3 / 2}\right)^{4}} \\
& =\frac{g}{\mu} \frac{d^{2}}{180} \frac{9\left(D^{7 / 2}-2 D^{5}+D^{13 / 2}\right) \dot{D}+6\left(D^{5}-D^{13 / 2}\right) \dot{D}}{2\left(1-D^{3 / 2}\right)^{4}} .
\end{aligned}
$$

In view of the permeability evolution of the fractured rock mass, with respect to the time $t$, the above variables can be transformed as

$$
\begin{aligned}
n(z, t) & =D(z, t)^{3 / 2}, \\
\dot{n}(z, t) & =\frac{3}{2} D(z, t)^{1 / 2} \dot{D}(z, t), \\
k(z, t) & =\frac{g}{\mu} \frac{d^{2}}{180} \frac{D(z, t)^{9 / 2}}{\left[1-D(z, t)^{3 / 2}\right]^{2}}=\frac{g}{\mu} \frac{d^{2}}{180} \frac{D(z, t)^{9 / 2}}{1-2 D(z, t)^{3 / 2}+D(z, t)^{3}}, \\
\dot{k}(z, t) & =\frac{g}{\mu} \frac{d^{2}}{180} \frac{3 n(z, t)^{2}[1-n(z, t)]^{2} \dot{n}(z, t)+2 n(z, t)^{3}[1-n(z, t)] \dot{n}(z, t)}{[1-n(z, t)]^{4}} \\
& =\frac{g}{\mu} \frac{d^{2}}{180} \frac{9\left[D(z, t)^{7 / 2}-2 D(z, t)^{5}+D(z, t)^{13 / 2}\right] \dot{D}(z, t)+6\left[D(z, t)^{5}-D(z, t)^{13 / 2}\right] \dot{D}(z, t)}{2\left[1-D(z, t)^{3 / 2}\right]^{4}} .
\end{aligned}
$$

Equations (30) and (31) are evolution equations of the permeability coefficient represented by $D$ and $\dot{D}$. When $D=0$ and $k(z, t)=0$, the rock mass is impervious and the porosity is $n(t, z)=0$. The initial damage is unavoidable in practical bedrocks with certain permeability. The grouting curtain will lose the impervious effectiveness when its permeability coefficient increases to that of the bedrocks, $D<1$ for this condition.

4.2. Numerical Simulation of the Seepage Evolution. The anisotropy equivalent permeability coefficient tensor should be known in advance in the numerical simulation. For infinitely extended and regularly arranged structural planes of the foundation faults, the equivalent permeability tensor is

$$
k_{i j}=\sum_{l=1}^{m} \frac{g b_{l}^{3}}{12 \mu S_{l}}\left(\delta_{i j}-n_{i}^{l} n_{j}^{l}\right),
$$

where $m$ is the grouping number of cracks; $b_{l}$ is the equivalent hydraulic gap width of the $l$ th group of fractures; $S_{l}$ is the spacing of cracks; $\delta_{i j}$ is the Kronecker symbol; $n_{i}^{l}$ $(i=1,2,3)$ is the cosine along the normal direction; $\mu$ is the kinematic viscosity coefficient.
If the viscous displacement is equivalent to an instantaneous stress increment, the equivalent stress increment of the viscous strain $\varepsilon_{k l}^{v}$ will be

$$
\Delta \sigma_{i j}^{v}=d_{i j k l} \varepsilon_{k l}^{v} .
$$

Let $K_{x^{\prime}}, K_{y^{\prime}}$, and $K_{z^{\prime}}$ be principal permeability coefficients of the permeability coefficient tensor. The effective principal stresses $\sigma_{\dot{x}}^{s}, \sigma_{\dot{y},}^{s}$ and $\sigma_{z}^{s}$ along the penetration principal axes can be obtained from the total stress $\sigma_{i j}+\Delta \sigma_{i j}^{v}$. According to the relationship between the permeability coefficient tensor and the stress $K=K_{0} e^{\lambda \sigma}$, the permeability coefficient under continuous loading is

$$
\left[K^{\prime}\right]=\left[\begin{array}{lll}
K_{x^{\prime}}\left(\lambda \sigma_{x^{\prime}}^{s}\right) & & \\
& K_{y^{\prime}}\left(\lambda \sigma_{y^{\prime}}^{s}\right) & \\
& & K_{z^{\prime}}\left(\lambda \sigma_{z^{\prime}}^{s}\right)
\end{array}\right],
$$

where $\lambda$ is an influence coefficient, determined by test results.

The rotation matrix between the infiltration principal axes and the global coordinates is recorded as $[T]$. The permeability coefficient tensor is

$$
[K]=[T]^{T}\left[K^{\prime}\right][T] .
$$


is

The seepage motion equation for the fractured rock mass

$$
\left(K_{i j, t} h_{, j}^{c}\right)_{, i}=0 \text {, }
$$

where $K_{i j, t}$ is the permeability tensor after the creep damage, deduced by equations (34) and (35); $h_{c}$ is the water head in continuous rock mass.

For 8-node isoparametric element, the governing equation is

$$
\left[K^{c}\right]^{e}\left\{h^{c}\right\}^{e}=\left\{Q^{c}\right\}^{e}
$$

where the component of $\left[K^{c}\right]^{e}$ is

$$
K_{a^{\prime} b}^{c}=\int_{\Omega^{e}} N_{a, i} K_{i j, t} N_{b, j} \mathrm{~d} \Omega, \quad\left(a^{\prime}, b^{\prime}=1 \sim 8 ; i, j=1 \sim 3\right) .
$$

The seepage influence of the fractured rock mass on its stress is considered as

$$
\vec{F}=\vec{F}_{s}+\vec{F}_{d}=\gamma_{w} \operatorname{grad}(z)-\gamma_{w} \operatorname{grad}(h),
$$

where $\gamma_{w}$ is the bulk density of water; $\vec{F}_{s}$ is the hydrostatic pressure, and its effect can be equivalent by an effective stress; $\vec{F}_{d}$ is the hydrodynamic pressure, considered as an external load in the calculation.

The equilibrium equation of the microelement considering the seepage is

$$
\left\{\begin{array}{l}
\frac{\partial \sigma_{x}}{\partial x}+\frac{\partial \tau_{x y}}{\partial y}+\frac{\partial \tau_{x z}}{\partial z}-\frac{\partial h}{\partial x}=0 \\
\frac{\partial \tau_{x y}}{\partial x}+\frac{\partial \sigma_{y}}{\partial y}+\frac{\partial \tau_{y z}}{\partial z}-\frac{\partial h}{\partial y}=0 \\
\frac{\partial \tau_{x z}}{\partial x}+\frac{\partial \tau_{y z}}{\partial y}+\frac{\partial \sigma_{z}}{\partial z}-\frac{\partial h}{\partial z}+\gamma_{w}-\gamma_{r}=0
\end{array}\right.
$$

where $\gamma_{r}$ is the saturated bulk density of rock; $h$ is the total water head.

Combining the stress-strain constitutive equation and the geometric equation, the equilibrium equations expressed by the displacement component and the water head are

$$
\left\{\begin{array}{l}
G \nabla^{2} \delta_{x}+\frac{G}{1-2 v} \frac{\partial \varepsilon_{v}}{\partial x}-\frac{\partial h}{\partial x}+X_{0}=0, \\
G \nabla^{2} \delta_{y}+\frac{G}{1-2 v} \frac{\partial \varepsilon_{v}}{\partial y}-\frac{\partial h}{\partial y}+Y_{0}=0, \\
G \nabla^{2} \delta_{z}+\frac{G}{1-2 v} \frac{\partial \varepsilon_{v}}{\partial z}-\frac{\partial h}{\partial z}+\gamma_{w}-\gamma_{r}=0,
\end{array}\right.
$$

where $G=E / 2(1+v)$ is the shear modulus; $\nabla^{2}=\left(\partial^{2} / \partial x^{2}\right)+$ $\left(\partial^{2} / \partial y^{2}\right)+\left(\partial^{2} / \partial z^{2}\right)$ is the Laplace operator; $\varepsilon_{v}=\varepsilon_{x}+\varepsilon_{y}+$ $\varepsilon_{z}=\left(\partial \delta_{x} / \partial x\right)+\left(\partial \delta_{y} / \partial y\right)+\left(\partial \delta_{z} / \partial z\right)$ is the volumetric strain; $X_{0}, Y_{0}$, and $Z_{0}$ are equivalent volume forces caused by the initial strain $\left\{\varepsilon_{0}\right\}$.
The equilibrium equation of the whole unit matrix derived from equation (41) is

$$
[K]^{e}\{\delta\}^{e}=\left\{F_{1}\right\}^{e}+\left\{F_{0}\right\}^{e}+\left[K^{\prime}\right]^{e}\{h\}^{e},
$$

where $\left\{F_{1}\right\}^{e}$ is the joint force caused by external loads; $\left\{F_{0}\right\}^{e}$ is the joint force caused by the initial strain; $\left[K^{\prime}\right]^{e}$ is the coupling matrix of the seepage and stress.

\section{Validation and Application}

The Longyangxia hydropower station is the first large-scale reservoir in the upper reaches of the Yellow River, with area of $383 \mathrm{~km}^{2}$ and storage capacity of 24.7 billion $\mathrm{m}^{3}$. It is composed of main dam, auxiliary dam, and discharge structures (shown in Figure 9). Dam concrete began to be poured in June 1982, and the diversion tunnel was put down to store water on October 15, 1986. The foundation elevation is $2432 \mathrm{~m}$, the dam crest elevation is $2610 \mathrm{~m}$, the maximum dam height is $178 \mathrm{~m}$, the dam length is $1227 \mathrm{~m}$ (including the main dam length of $396 \mathrm{~m}$ ), the dam crest width is $23.5 \mathrm{~m}$, and the maximum bottom width is $80 \mathrm{~m}$.

The dam foundation is granodiorite with hard lithology. The dam abutment faults develop well through complex geotectonic movement and the main faults are shown in Figure 10. Most of the NE-trending faults are filled with wide quartzite veins and form altered rock belts, among which the larger ones are the $F_{120}$ fault and the $A_{2}$ quartzite, located at the right bank. The $F_{120}$ fault locates in the deep part near the dam abutment, with width of $2 \mathrm{~m} \sim 6 \mathrm{~m}$ and poor behavior, and its strike is nearly orthogonal to the thrust direction of the dam. The filled mylonite and breccia are not very continuous, but there is a fully and strongly weathered altered rock zone with an average thickness of $1.2 \mathrm{~cm}$. The $A_{2}$ quartzite has a pulse width of $5 \mathrm{~m} \sim 10 \mathrm{~m}$. Its NE-trending vertical fractures and nearly horizontal fractures develop well, with strong water permeability. The $F_{120}+A_{2}$ affected zone has several to tens of centimeters of intercalated mud containing breccia and detritus, which are dense and impervious to the leakage water. However, the fractured rock mass in the $F_{120}+A_{2}$ zone constitutes a network-like seepage channel with strong permeability, and the seepage damage has always been in progress under the high hydraulic pressures.

The reservoir water level change is shown in Figure 11. Since 1986, the water level had never reached the design water level of $2600 \mathrm{~m}$ during 27 years of operation, but it rose continuously in the flood season of 2005 from $2558.70 \mathrm{~m}$ on April 26th to $2597.62 \mathrm{~m}$ on November 19th. As shown in Figure 11, the leakage at the $F_{120}+A_{2}$ fault increased obviously and the monitoring leakage at $2463 \mathrm{~m}$ elevation increased by $252.7 \mathrm{~mL} / \mathrm{s}$ during the water rising period.

5.1. Validation by the 2D Model Simulation. An impervious curtain was formed in the fractured rock mass of the dam foundation after grouting, which could prolong the seepage path and reduce the seepage pressure. However, the curtain rock mass was gradually damaged under the long-term action of the stress field, the temperature field, and the 


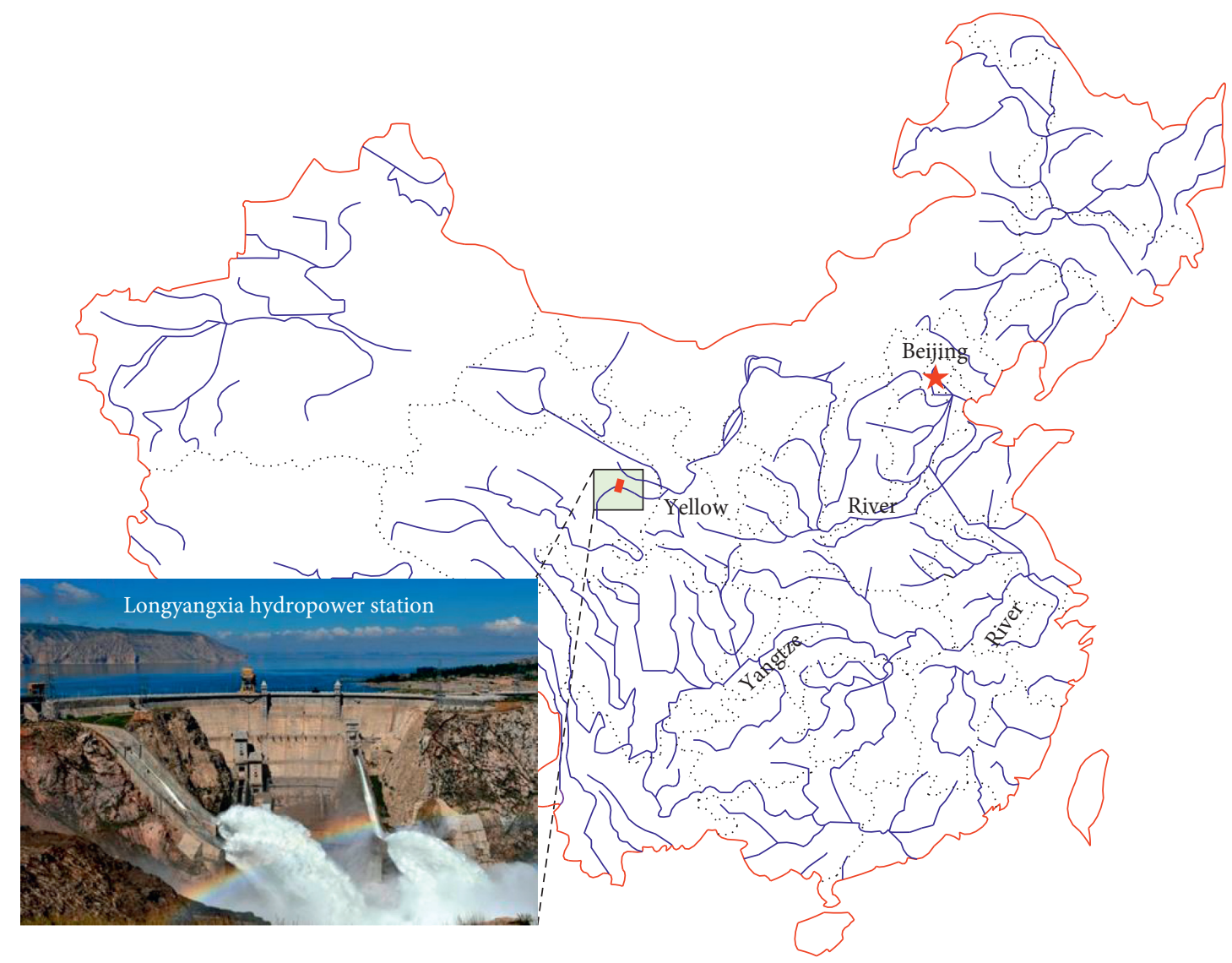

Figure 9: The Longyangxia hydropower station.

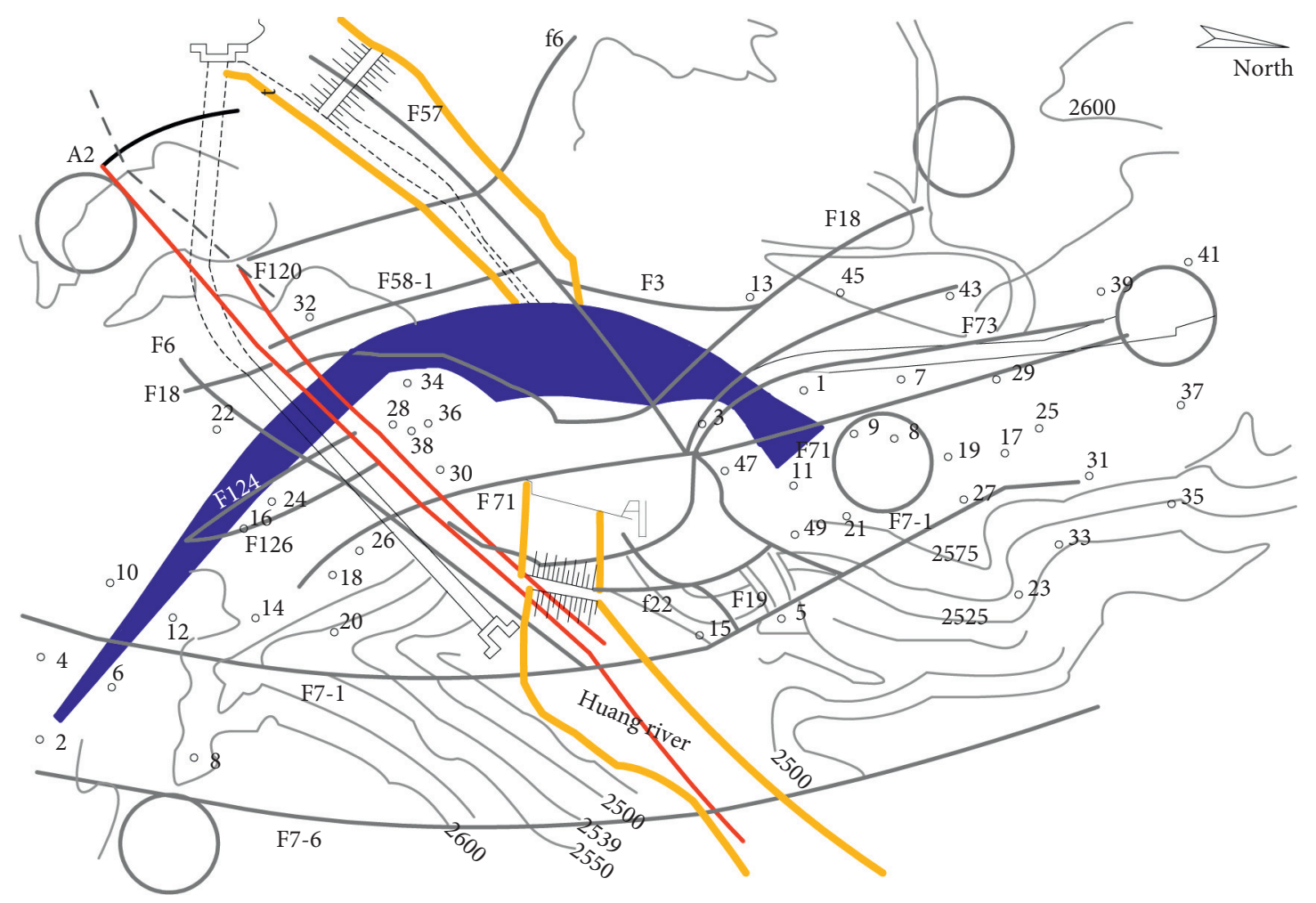

Figure 10: Distribution of main faults and layout of the groundwater monitoring holes. 


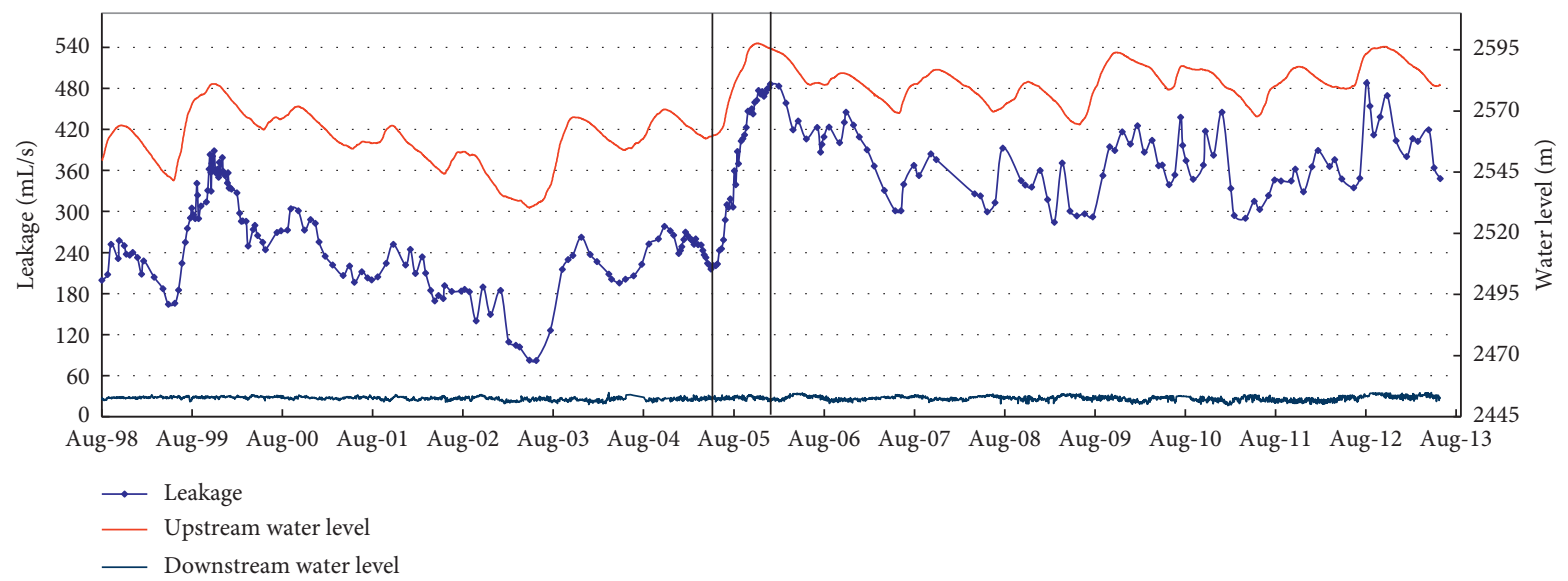

Figure 11: Measured time series of the leakage at $2463 \mathrm{~m}$ elevation of the $F_{120}+A_{2}$ fault.

seepage field. To simulate the situation, a 2-dimensional finite element model is firstly established, shown in Figure 12, where the $F_{120}+A_{2}$ fault passes through the gravity pier on the right bank (the foundation elevation is $2580 \mathrm{~m}$ ). The model range is as follows: the length near the upstream gravity pier is 10 times of the curtain depth, the length near the downstream gravity pier is 3 times, and it is 10 times along the depth. Displacement-pore pressure quadrilateral coupling element is used for modelling. Convergence tests have been implemented to determine the number of elements and nodes: 57131 coupling elements and 57624 nodes in total.

Through geological prospecting, the permeability coefficient of the layered fault decreases along the depth. According to the GB 50487-2008 (code for engineering geological investigation of water resources and hydropower), the permeability coefficient range is $10^{-4} \leq k$ $<10^{-2} \mathrm{~m} / \mathrm{s}$. In this study, the $F_{120}+A_{2}$ fault is divided into ten layers of rock 1 - rock 10 (shown in Figure 12(b)) and the main parameters are listed in Table 1. The permeability coefficients are distributed as an exponential function with depth, as shown in Figure 13.

The proposed methods are used to study the variation laws of the seepage field of the dam foundation. When the damage variables of the $F_{120}+A_{2}$ fault at different depths are $0.10-0.55$, the corresponding increment distributions of the permeability coefficient and the rock porosity are shown in Figure 14. They all increase gradually when the damage continues to develop, and they decrease along the rock depth, due to the rock mass confining pressures.

Take 16 groups of calculating conditions for illustration, where the impervious curtain rock mass damage is $0.1-0.84$, respectively, with the upstream normal water level of $2600 \mathrm{~m}$ and the downstream water level of $2450 \mathrm{~m}$. According to equations (28) and (30), when different damage variables are taken for the curtain rock mass, corresponding curtain porosities and relative coefficients (the ratio of the curtain rock mass permeability coefficient to the first rock stratum permeability coefficient) are shown in Figure 15. The piezometer head values $\mathrm{H}_{2}$ at a typical point behind the curtain and corresponding osmotic pressure coefficient $\alpha_{2}$ both increase gradually. When the damage degree reaches 0.84 , the seepage control of the curtain rock mass can be considered completely lost, since the relative coefficient equals 1 .

The variations of the pore water pressure in the exposed local area of the downstream slope under different damage degrees are shown in Figure 16. With the increase of the damage degree, the saturation line of the exposed local area gradually rises, indicating that the impervious curtain gradually weakens and also verifies the effectiveness of the proposed methods.

5.2. Application on the 3D Model Simulation. According to the distribution of the main faults in Figure 10, the 3D finite element model is established, as shown in Figure 17, including the main boundary range that affects the seepage behavior. The model range is 1 time the dam height on the left and right banks, $761 \mathrm{~m}$ in total, and the upstream and downstream length is $613 \mathrm{~m}$. The model simulates the arch dam, the foundation rock mass, main faults, and antiseepage curtain, especially the $F_{120}+A_{2}$ fault and the sandwiched mud. After convergence tests, there are 27,291 nodes and 24,631 elements.

The simulation of the seepage field primarily considers the following boundary conditions. (1) Interception boundary of the regional basement: the foundation depth of the $3 \mathrm{D}$ model is $314.8 \mathrm{~m}$, which is 2 times the curtain depth and it is treated as an impervious boundary condition. (2) The upstream and downstream interception boundary of the dam located area is treated as an impervious boundary. (3) Known boundary of the reservoir water level: the highest water level reached in 2005 is $2597.62 \mathrm{~m}$ upstream and $2453.52 \mathrm{~m}$ downstream at the corresponding time. The riverbed below the upstream and downstream water levels is regarded as the known boundary of constant water head. (4) Possible overflow boundaries are regarded as possible seepage boundaries, including the surfaces above the riverbed water level downstream and the intercepted boundary below the water level at the two banks. (5) Interception 


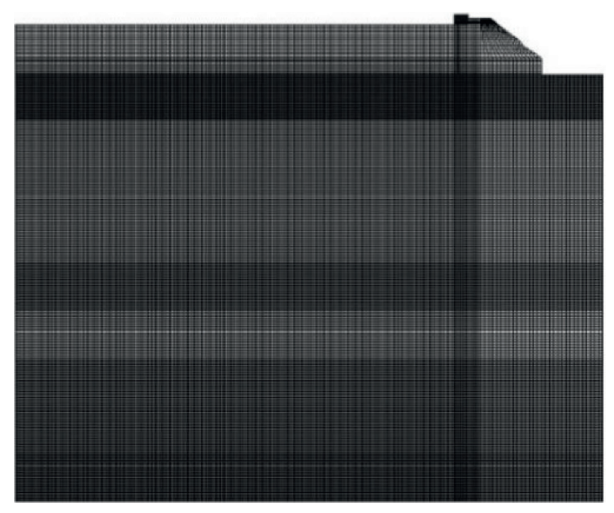

(a)

\begin{tabular}{|l|}
\hline The $1^{\text {st }}$ layer \\
\hline The $2^{\text {nd }}$ layer \\
\hline The $3^{\text {rd }}$ layer \\
\hline The $4^{\text {th }}$ layer \\
\hline The $5^{\text {th }}$ layer \\
\hline The $6^{\text {th }}$ layer \\
\hline The $7^{\text {th }}$ layer \\
\hline The $8^{\text {th }}$ layer \\
\hline The $9^{\text {th }}$ layer \\
\hline The $10^{\text {th }}$ layer \\
\hline
\end{tabular}

Gravity pier

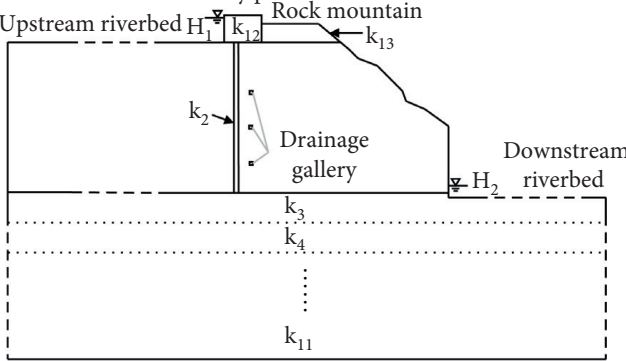

(b)

FIgURE 12: 2D model and the zoning results of the dam foundation. (a) $2 \mathrm{D}$ finite element model; (b) divisions of the $F_{120}+A_{2}$ fault.

TABLE 1: Material mechanical and seepage parameters.

\begin{tabular}{|c|c|c|c|c|}
\hline Zone & Elastic modulus (MPa) & Poisson's ratio & Intensity $\left(\mathrm{kg} / \mathrm{m}^{3}\right)$ & Permeability coefficient $(\mathrm{m} / \mathrm{s})$ \\
\hline Gravity pier & $2.8 \times 10^{4}$ & 0.167 & 2400 & $k_{12}=1.0 \times 10^{-7}$ \\
\hline Downstream rock mountain & $2.0 \times 10^{4}$ & 0.22 & 2600 & $k_{13}=1.0 \times 10^{-6}$ \\
\hline Curtain & $2.8 \times 10^{4}$ & 0.167 & 2600 & $k_{2}=1.0 \times 10^{-7}$ \\
\hline The $1^{\text {st }}$ rock layer & $5.4 \times 10^{3}$ & 0.2 & 2600 & $k_{1}=2.64 \times 10^{-4}$ \\
\hline The $2^{\text {nd }}$ rock layer & $5.4 \times 10^{3}$ & 0.2 & 2600 & $k_{3}=2.32 \times 10^{-4}$ \\
\hline The $3^{\text {rd }}$ rock layer & $5.4 \times 10^{3}$ & 0.2 & 2600 & $k_{4}=2.04 \times 10^{-4}$ \\
\hline The $4^{\text {th }}$ rock layer & $5.4 \times 10^{3}$ & 0.2 & 2600 & $k_{5}=1.79 \times 10^{-4}$ \\
\hline The $5^{\text {th }}$ rock layer & $5.4 \times 10^{3}$ & 0.2 & 2600 & $k_{6}=1.58 \times 10^{-4}$ \\
\hline The $6^{\text {th }}$ rock layer & $5.4 \times 10^{3}$ & 0.2 & 2600 & $k_{7}=1.39 \times 10^{-4}$ \\
\hline The $7^{\text {th }}$ rock layer & $5.4 \times 10^{3}$ & 0.2 & 2600 & $k_{8}=1.22 \times 10^{-4}$ \\
\hline The $8^{\text {th }}$ rock layer & $5.4 \times 10^{3}$ & 0.2 & 2600 & $k_{9}=1.07 \times 10^{-4}$ \\
\hline The $9^{\text {th }}$ rock layer & $5.4 \times 10^{3}$ & 0.2 & 2600 & $k_{10}=9.42 \times 10^{-5}$ \\
\hline The $10^{\text {th }}$ rock layer & $5.4 \times 10^{3}$ & 0.2 & 2600 & $k_{11}=8.28 \times 10^{-5}$ \\
\hline
\end{tabular}

boundary of the two banks: the distribution of the groundwater is simulated with the measured data of groundwater level holes (Figure 10) to obtain the calculation boundary. The water head on November 19, 2005, is selected for the simulation. The permeability coefficient values of each region are listed in Table 2.

In order to obtain the leakage through the $\mathrm{F}_{120}+A_{2}$ fault, the flow velocities of the elements corresponding to $2463 \mathrm{~m}$, $2497 \mathrm{~m}$, and $2530 \mathrm{~m}$ below the saturation lines after the curtain are extracted, and the element areas corresponding to the fault from $2463 \mathrm{~m}$ to $2497 \mathrm{~m}$, from $2497 \mathrm{~m}$ to $2530 \mathrm{~m}$, and from $2530 \mathrm{~m}$ to the saturation line are calculated.
Figure 18(a) indicates the seepage extraction cross section through the $\mathrm{F}_{120}+A_{2}$ fault. The saturation lines at the highest water level of $2597.62 \mathrm{~m}$ are shown in Figure 18(b). The leakages passing the $2463 \mathrm{~m}$ elevation, the $2497 \mathrm{~m}$ elevation, and the $2530 \mathrm{~m}$ elevation of the fault are calculated. The results and corresponding measured data are listed in Table 3.

The calculated results at typical elevations significantly increase during the rise of the reservoir water level and are in good agreement with the measured values. With the increase of the permeability coefficient, the $F_{120}+A_{2}$ fault becomes the main leakage channel, and the grouted curtain has 


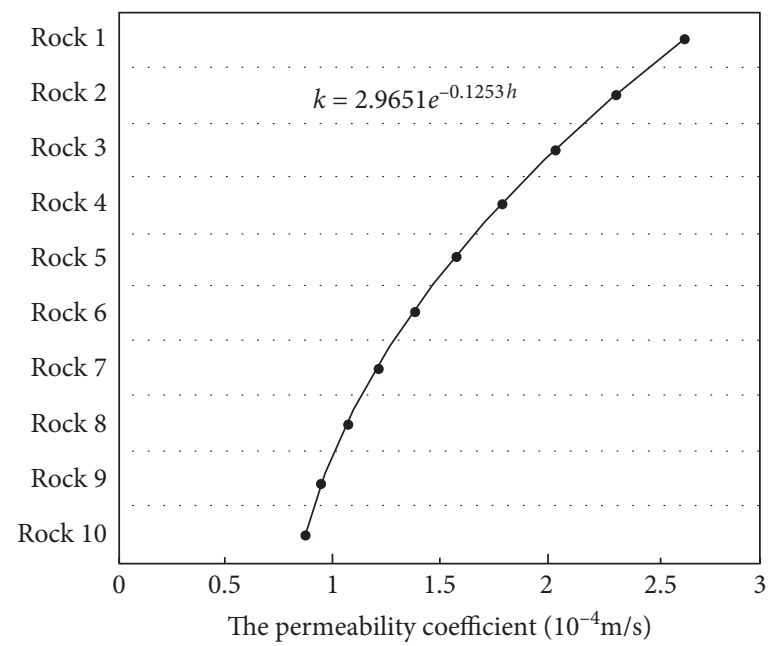

FIgURE 13: Distribution of permeability coefficient of the $F_{120}+A_{2}$ fault along the depth.

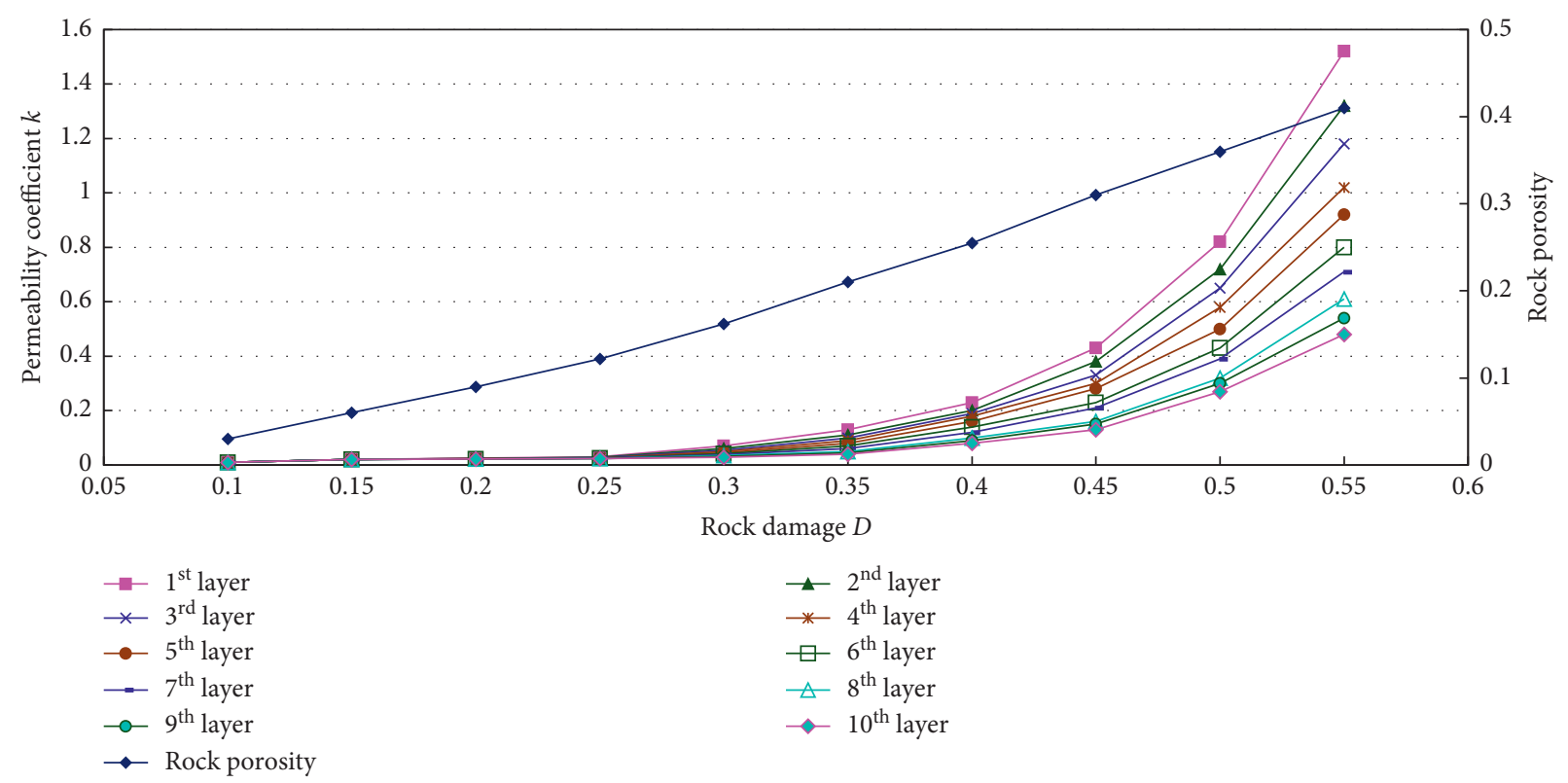

FIGURE 14: Evolution of the permeability coefficients of the $1^{\text {st }}-11^{\text {th }}$ rock layer.

significant effect to reduce the seepage water head. The results also indicate that the water inflow rate is primarily affected by both the hydraulic conductivity and induced microcracks of the damage fault during the storage period. Once the curtain fails, the water level at each measured pore will become higher and the corresponding leakage amount will also increase obviously.

According to the simulated and measured results, the seepage of the dam foundation on the right bank has a remarkable correlation with the change of the reservoir, but there has not been a persistent increase phenomenon. Namely, the seepage behavior has not deteriorated, and it is not necessary to repair the curtain temporarily. Because the high seepage pressures will gradually increase the damage of fractured rock mass, it is also suggested that the monitoring of the fault leakage should be paid special attention during the future operation, especially the high reservoir water period. If necessary, the drainage facilities of the dam foundation should be newly added to reduce the seepage pressure and ensure the safe operation of the dam. 


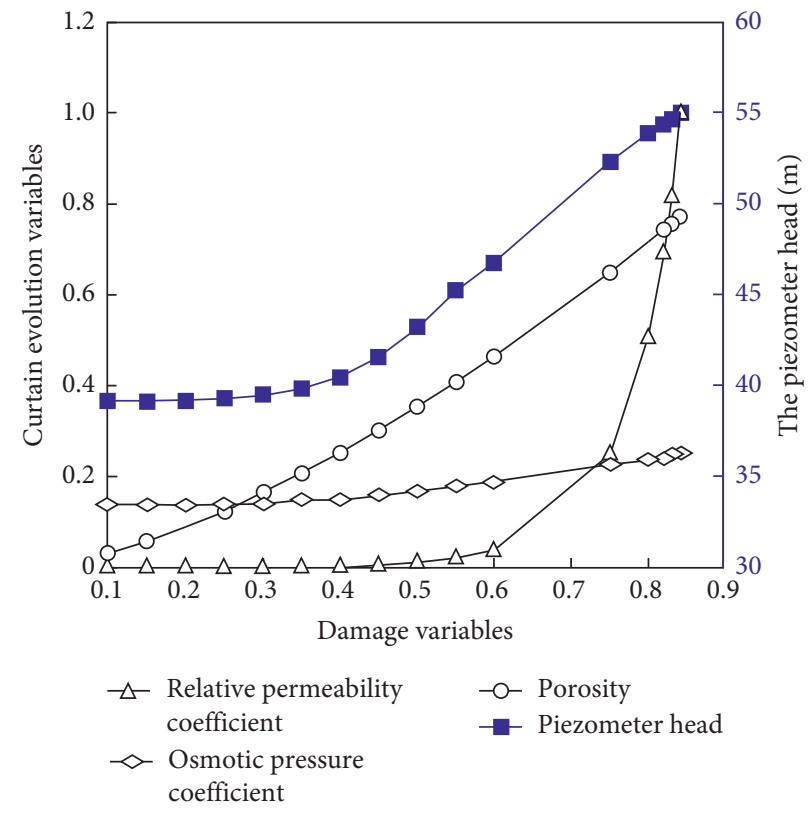

Figure 15: Damage evolution of the permeability characteristics of the curtain rock mass.

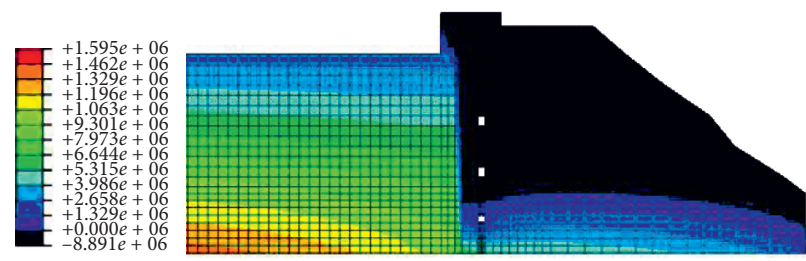

(a)

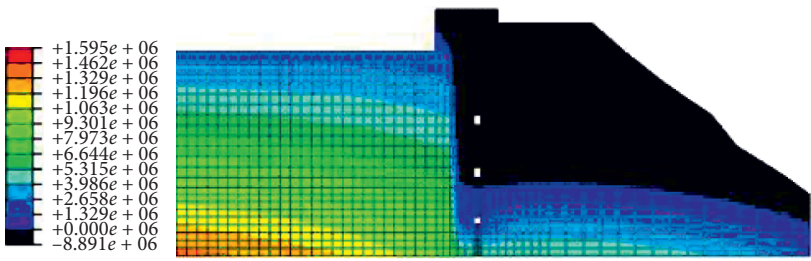

(c)

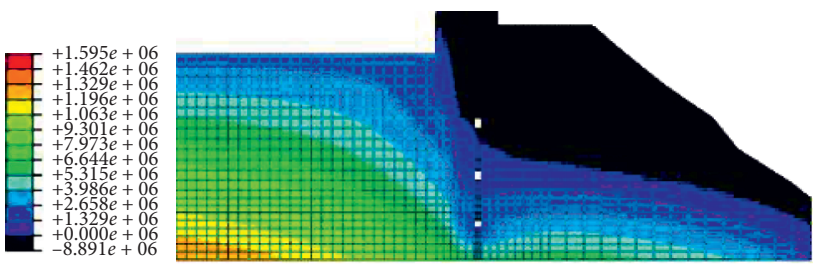

(e)

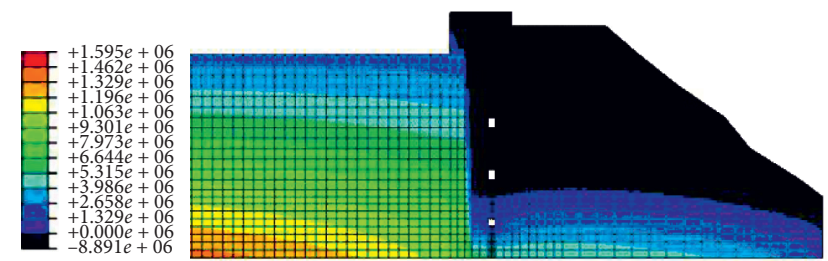

(b)

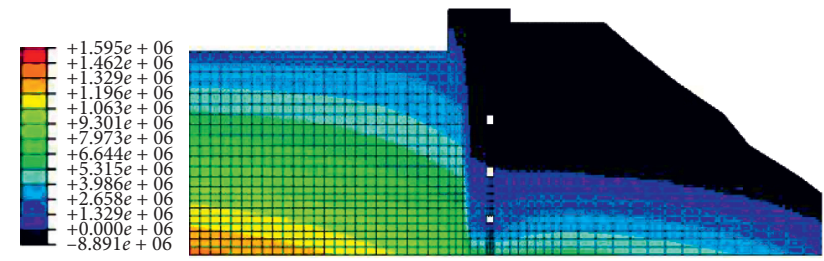

(d)

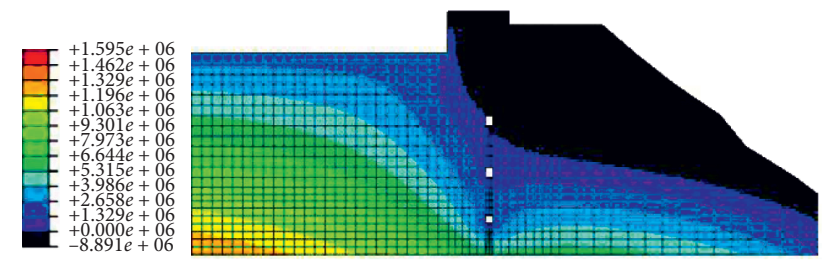

(f)

FIGURE 16: Distributions of the pore water pressure of the fractured rock mass (unit: Pa). (a) $D=0.1$, (b) $D=0.45$, (c) $D=0.5$, (d) $D=0.6,(\mathrm{e})$ $D=0.75$, and (f) $D=0.84$. 


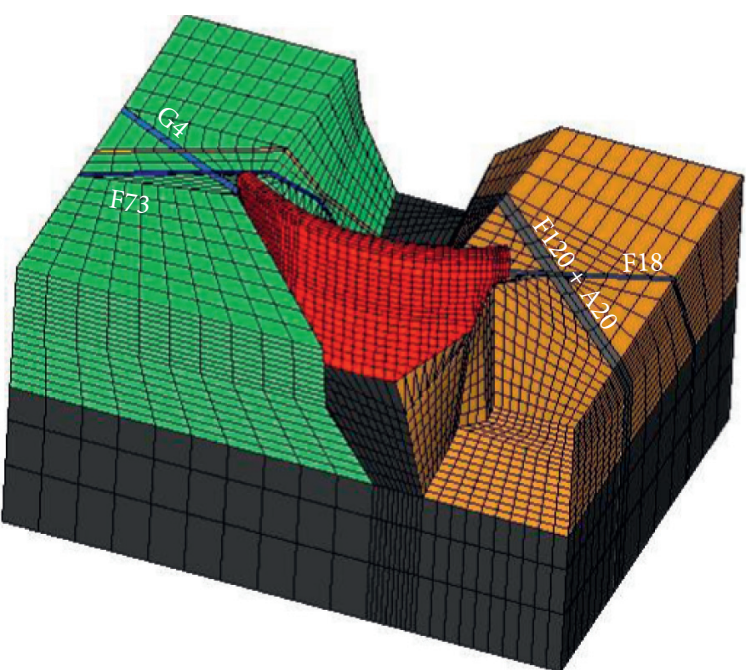

Figure 17: The 3D model of the Longyangxia dam.

TABle 2: Permeability coefficients of each region in the 3D model.

\begin{tabular}{lcccccc}
\hline Material zone & Shallow rock mass & Deep rock mass & The curtain & The $G_{4}$ fault & The $F_{18}$ fault & The $F_{73}$ fault \\
\hline Permeability coefficient $(\mathrm{m} / \mathrm{s})$ & $5.0 \times 10^{-6}$ & $2.0 \times 10^{-6}$ & $1.0 \times 10^{-7}$ & $1.0 \times 10^{-6}$ & $1.0 \times 10^{-6}$ & $1.0 \times 10^{-6}$ \\
\hline
\end{tabular}

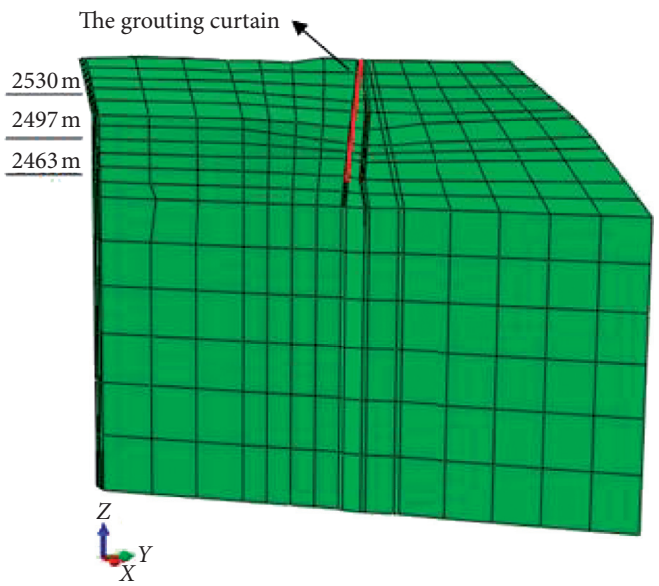

(a)

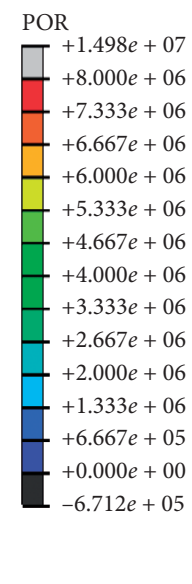

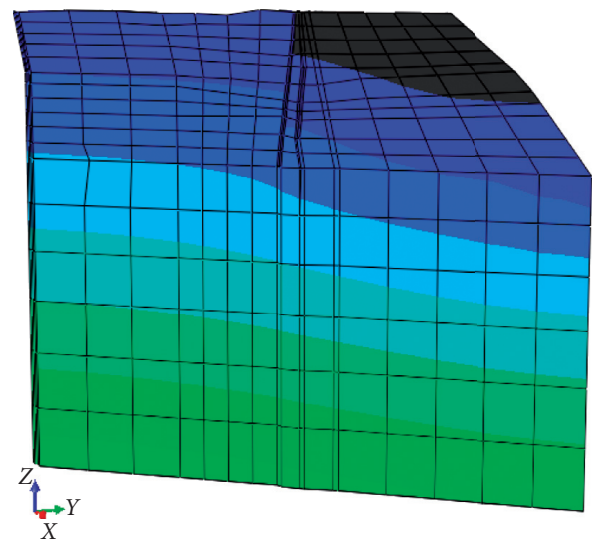

(b)

Figure 18: The $F_{120}+A_{2}$ fault model and the calculated saturation lines. (a) Seepage extraction cross section; (b) the saturation line with water level of $2597.62 \mathrm{~m}$.

TABLE 3: Calculation results of the leakages through the $F_{120}+A_{2}$ fault $(\mathrm{mL} / \mathrm{s})$.

\begin{tabular}{|c|c|c|c|c|c|c|}
\hline \multirow{2}{*}{ Storage date (water level) } & \multicolumn{2}{|c|}{$2463 \mathrm{~m}$ elevation } & \multicolumn{2}{|c|}{2497 m elevation } & \multicolumn{2}{|c|}{$2530 \mathrm{~m}$ elevation } \\
\hline & Calculated & Measured & Calculated & Measured & Calculated & Measured \\
\hline $2005-6-4(2575.45 \mathrm{~m})$ & 322.49 & 318.65 & 359.35 & 265.81 & 224.79 & 219.56 \\
\hline $2005-8-18(2580.85 \mathrm{~m})$ & 359.28 & 359.45 & 377.98 & 385.12 & 238.82 & 227.72 \\
\hline $2005-10-5(2591.54 \mathrm{~m})$ & 431.51 & 422.89 & 567.36 & 527.17 & 290.61 & 292.35 \\
\hline $2005-11-16(2597.62 \mathrm{~m})$ & 470.22 & 462.8 & 584.83 & 580.79 & 315.96 & 332.9 \\
\hline
\end{tabular}




\section{Conclusions}

The mechanical characteristics of the fractured rock mass in seepage fields and the interaction mechanism of water-rock are critical for evaluation of the instability of dam foundations and even large-scale geological disasters. In this work, the creep damage and its effect on the permeability evolution are investigated combining with multiple test evidences. The permeability of the fractured rock mass can significantly increase with the growth and coalescence of microcracks under certain seepage pressures. Hence, the creep damage constitutive models are established to indicate the strength weakening under continuous loads. The evolution equation of the permeability coefficient is furtherly constructed with the crack tensor to characterize the mechanical behavior under the seepage-compression and shear action.

The proposed approaches are applied to the Longyangxia dam and the simulated results agree well with the measured values, indicating that the presented model can describe the permeability variation of the $F_{120}+A_{2}$ fault. It was further confirmed that the seepage pressures can intensify the crack expansion and penetration in the rock masses and may lead to the gradual failure of the foundation. As the leakage behavior of dam foundations is constantly changing due to the transformation of the seepage pressures, compared to preexisting models, the presented microcrack-based creep damage and seepage coupled method is capable of appraising the fracturing evolution and the leakage variation in the fractured rock mass of practical dam foundations. The research results can also provide a reference for engineering repair and supervision through controlling the permeability performance. For the future work, the criteria for judging the change of the seepage behavior of dam foundations and the early warning indicators need to be further studied for detecting the potential dangers in time.

\section{Data Availability}

All data used in this study are available from the corresponding author upon request.

\section{Conflicts of Interest}

The authors declare that there are no known conflicts of interest.

\section{Acknowledgments}

This work was supported by the National Natural Science Foundation of China (Grant nos. 51779086, 52079046, and 51739003) and the Fundamental Research Funds for the Central Universities (Grant no. B210202017).

\section{References}

[1] G. Barla, Q. Fan, and L. Peng, "Introduction to the special issue "super high arch dams and underground caverns in China," Rock Mechanics and Rock Engineering, vol. 51, no. 8, pp. 2447-2450, 2018.
[2] Y.-F. Chen, X.-M. Ling, M.-M. Liu, R. Hu, and Z. Yang, "Statistical distribution of hydraulic conductivity of rocks in deep-incised valleys, Southwest China," Journal of Hydrology, vol. 566, pp. 216-226, 2018.

[3] T. S. Nemer, "The Bisri dam project: a dam on the seismogenic Roum fault, Lebanon,” Engineering Geology, vol. 261, Article ID 105270, 2019.

[4] W. Ehlers and C. Luo, "A phase-field approach embedded in the theory of porous media for the description of dynamic hydraulic fracturing," Computer Methods in Applied Mechanics and Engineering, vol. 315, pp. 348-368, 2017.

[5] R. Liu, L. Yu, Y. Jiang, Y. Wang, and B. Li, "Recent developments on relationships between the equivalent permeability and fractal dimension of two-dimensional rock fracture networks," Journal of Natural Gas Science and Engineering, vol. 45, pp. 771-785, 2017.

[6] T. Wang, J. Chen, P. Li, Y. Yin, C. J. Shen, and C. Shen, "Natural tracing for concentrated leakage detection in a rockfill dam," Engineering Geology, vol. 249, pp. 1-12, 2019.

[7] P. Duffaut, "The traps behind the failure of Malpasset arch dam, France, in 1959," Journal of Rock Mechanics and Geotechnical Engineering, vol. 5, no. 5, pp. 335-341, 2013.

[8] S. Q. Ding, "The cause and stability analysis after treatment of 1962 accidents in Meishan Reservoir in Anhui province," Resources Environment \& Engineering, vol. 22, no. s1, pp. 83-85, 2008.

[9] Z. Huang, Z. Jiang, S. Zhu, X. Wu, L. Yang, and Y. Guan, "Influence of structure and water pressure on the hydraulic conductivity of the rock mass around underground excavations," Engineering Geology, vol. 202, pp. 74-84, 2016.

[10] G. Dennis, H. Rainer, F. Bernd, and C. Holger, "A discrete fracture model for two-phase flow in fractured porous media," Advances in Water Resources, vol. 110, pp. 335-348, 2017.

[11] X. Y. Liu, Z. D. Zhu, A. H. Liu, and Y. Tian, "Lognormal distribution function for describing seepage damage process of single-cracked rock," Advances in Civil Engineering, vol. 2020, Article ID 8838670, 11 pages, 2020.

[12] X. M. Zhu, G. N. Liu, F. Gao, D. Y. Ye, and J. X. Luo, “A complex network model for analysis of fractured rock permeability," Advances in Civil Engineering, vol. 2020, Article ID 8824082, 10 pages, 2020.

[13] P. Xu, C. H. Li, S. X. Qiu, and S. Agus Pulung, "A fractal network model for fractured porous media," Fractals, vol. 24, no. 2, pp. 1-9, 2016.

[14] Q. Zhang, C. Wang, and W. Xiang, "A seepage-stress coupling model in fractured porous media based on XFEM," Geotechnical and Geological Engineering, vol. 37, no. 5, p. 4057, 2019.

[15] W. Shi and T. Yang, "A coupled nonlinear flow model for particle migration and seepage properties of water inrush through broken rock mass," Geofluids, vol. 2020, Article ID 1230542, 14 pages, 2020.

[16] B. Figueiredo, C.-F. Tsang, J. Rutqvist, and A. Niemi, “A study of changes in deep fractured rock permeability due to coupled hydro-mechanical effects," International Journal of Rock Mechanics and Mining Sciences, vol. 79, pp. 70-85, 2015.

[17] Q. Gan and D. Elsworth, "A continuum model for coupled stress and fluid flow in discrete fracture networks," Geomechanics and Geophysics for Geo-Energy and Geo-Resources, vol. 2, no. 1, pp. 43-61, 2016.

[18] R. Liu, B. Li, Y. Jiang, and L. Yu, "A numerical approach for assessing effects of shear on equivalent permeability and nonlinear flow characteristics of 2-D fracture networks," Advances in Water Resources, vol. 111, pp. 289-300, 2018. 
[19] G. Pappalardo, "First results of infrared thermography applied to the evaluation of hydraulic conductivity in rock masses," Hydrogeology Journal, vol. 26, no. 2, pp. 417-428, 2018.

[20] F. Ren, G. Ma, L. Fan, Y. Wang, and H. Zhu, "Equivalent discrete fracture networks for modelling fluid flow in highly fractured rock mass," Engineering Geology, vol. 229, pp. 21-30, 2017.

[21] N. Sundararajan and S. Sankaran, "Groundwater modeling of Musi basin Hyderabad, India: a case study," Applied Water Science, vol. 10, pp. 1-14, 2020.

[22] Q. Zhang, Y. Ju, W. Gong, L. Zhang, and H. Sun, "Numerical simulations of seepage flow in rough single rock fractures," Petroleum, vol. 1, no. 3, pp. 200-205, 2015.

[23] M. Wang, Y.-F. Chen, R. Hu, W. Liu, and C.-B. Zhou, "Coupled hydro-mechanical analysis of a dam foundation with thick fluvial deposits: a case study of the Danba Hydropower Project, Southwestern China," European Journal of Environmental and Civil Engineering, vol. 20, no. 1, pp. 19-44, 2016.

[24] C.-B. Zhou, W. Liu, Y.-F. Chen, R. Hu, and K. Wei, "Inverse modeling of leakage through a rockfill dam foundation during its construction stage using transient flow model, neural network and genetic algorithm," Engineering Geology, vol. 187, pp. 183-195, 2015.

[25] C.-B. Zhou, X.-J. Zhao, Y.-F. Chen, Z. Liao, and M.-M. Liu, "Interpretation of high pressure pack tests for design of impervious barriers under high-head conditions," Engineering Geology, vol. 234, pp. 112-121, 2018.

[26] X. Li, Y. Chen, R. Hu, and Z. Yang, "Towards an optimization design of seepage control: a case study in dam engineering," Science China Technological Sciences, vol. 60, no. 12, pp. 1903-1916, 2017.

[27] D. Ma, X. X. Miao, G. H. Jiang, H. B. Bai, and Z. Q. Chen, “An experimental investigation of permeability measurement of water flow in crushed rocks," Transport in Porous Media, vol. 105, no. 3, pp. 571-595, 2014.

[28] Y. Yuan, J. Fu, X. Wang, and X. Shang, "Experimental study on mechanical properties of prefabricated single-cracked red sandstone under uniaxial compression," Advances in Civil Engineering, vol. 2020, Article ID 8845368, 14 pages, 2020.

[29] H. Kong and L. Wang, "The behavior of mass migration and loss in fractured rock during seepage," Bulletin of Engineering Geology and the Environment, vol. 79, no. 2, pp. 739-754, 2020.

[30] H. Kong and L. Wang, "The mass loss behavior of fractured rock in seepage process: the development and application of a new seepage experimental system," Advances in Civil Engineering, vol. 2018, Article ID 7891914, 12 pages, 2018.

[31] S. Yang, H. W. Zhou, S. Q. Zhang, and W. G. Ren, "A fractional derivative perspective on transient pulse test for determining the permeability of rocks," International Journal of Rock Mechanics and Mining Sciences, vol. 113, pp. 92-98, 2019.

[32] Q. Jiang, X. Liu, F. Yan et al., "Failure performance of 3DP physical twin-tunnel model and corresponding safety factor evaluation," Rock Mechanics and Rock Engineering, vol. 54, pp. 109-128, 2020.

[33] Z. Li, H. Liu, Z. Dun, L. Ren, and J. Fang, "Grouting effect on rock fracture using shear and seepage assessment," Construction and Building Materials, vol. 242, Article ID 118131, 2020.

[34] D. X. Liang, "Study on the damage evolution mechanism of fractured rock mass under high seepage pressure,"
Dissertation, China University of Mining \& Technology, Xuzhou, China, 2016.

[35] H. T. Zhou, "Study on the pressure seepage evolution characteristics and hydraulic mechanism of fractured rock mass," Dissertation, China University of Mining \& Technology, Xuzhou, China, 2017.

[36] S. Huang, X. Meng, G. Zhao et al., "Creep mechanics of the high-stress soft rock under grade unloading," Advances in Civil Engineering, vol. 2020, Article ID 8822265, 12 pages, 2020.

[37] W.-Y. Xu, R.-B. Wang, W. Wang, Z.-L. Zhang, J.-C. Zhang, and W.-Y. Wang, "Creep properties and permeability evolution in triaxial rheological tests of hard rock in dam foundation," Journal of Central South University, vol. 19, no. 1, pp. 252-261, 2012.

[38] P. Zhang, Z.-Y. Yin, Y.-F. Jin, T. H. T. Chan, and T. H. T. Chan, "A novel hybrid surrogate intelligent model for creep index prediction based on particle swarm optimization and random forest," Engineering Geology, vol. 265, Article ID 105328, 2020.

[39] M. Karalar and M. Çavuşli, "Examination of 3D long-term viscoplastic behaviour of a CFR dam using special material models," Geomechanics and Engineering, vol. 17, no. 2, pp. 119-131, 2019.

[40] M. Karalar and M. Çavuşli, "Seismic effects of epicenter distance of earthquake on 3D damage performance of CG dam," Earthquakes and Structures, vol. 18, no. 2, pp. 201-213, 2020.

[41] A. Pouya and P. Bemani Yazdi, "A damage-plasticity model for cohesive fractures," International Journal of Rock Mechanics and Mining Sciences, vol. 73, pp. 194-202, 2015.

[42] Z. Li, H. Zhou, D. W. Hu, and C. Q. Zhang, "Yield criterion for rocklike geomaterials based on strain energy and CMP model," International Journal of Geomechanics, vol. 20, no. 3, Article ID 04020013, 2020.

[43] W. Z. Chen, G. J. Wu, J. P. Yang, S. P. Jian, and Y. H. Dai, Stability Analysis Theory and Engineering Application of Underground Engineering in Fractured Rock Mass, Science Press, Beijing, China, 2012. 